Portland State University

PDXScholar

Fall 11-16-2018

\title{
Early Detection of Corrosion via Hydrogel-based Spectroelectrochemical Sensors
}

\author{
Capri Ann Price \\ Portland State University
}

Follow this and additional works at: https://pdxscholar.library.pdx.edu/open_access_etds

Part of the Chemistry Commons, and the Materials Science and Engineering Commons Let us know how access to this document benefits you.

\section{Recommended Citation}

Price, Capri Ann, "Early Detection of Corrosion via Hydrogel-based Spectroelectrochemical Sensors" (2018). Dissertations and Theses. Paper 4637.

https://doi.org/10.15760/etd.6521

This Dissertation is brought to you for free and open access. It has been accepted for inclusion in Dissertations and Theses by an authorized administrator of PDXScholar. Please contact us if we can make this document more accessible: pdxscholar@pdx.edu. 
Early Detection of Corrosion via Hydrogel-based Spectroelectrochemical Sensors

$$
\text { by }
$$

\title{
Capri Ann Price
}

\begin{abstract}
A dissertation submitted in partial fulfillment of the requirements for the degree of
\end{abstract}

\author{
Doctor of Philosophy \\ in \\ Chemistry
}

\author{
Dissertation Committee: \\ Tami L. Clare, Chair \\ Steve Reichow \\ Dean Atkinson \\ James Pankow \\ Rolf Koenenkamp
}

Portland State University 
C 2018 Capri Ann Price 


\begin{abstract}
The backbone of the industrialized world is comprised of refined, zerovalent metal, a material which thermodynamically favors an oxidative return to more chemically stable states. There are many methods used to slow or delay this process, such as protective coatings, sacrificial anodes, and alloys, but no method can entirely prevent corrosion. This body of work instead proposes detecting the earliest chemical markers of corrosion: that is, metal ions as they solubilize from a metal surface. Such information would allow maintenance personnel to make informed decisions about the necessity or lack thereof of preventive maintenance, and intervene before advanced damage has a chance to occur.
\end{abstract}

This dissertation finds that hydrogel-based sensors are capable of such detection and offer a multisensory response, with colorimetric, electrical, volumetric and vibrational changes. Both the colorimetric and electrical trends were calibrated and used for quantification of metal ions both in solution and directly from metal substrate surfaces. Observing how the hydrogels responded to various metal ions contributed to a greater understanding of how ion-headgroup associations can affect the sensory responses of a hydrogel, something that can be exploited in future sensor work. The ability of the sensors to detect ions directly from metal surfaces allowed for an investigation of the protective quality of fatty acids as corrosion inhibitors. A range of chain lengths were tested using the hydrogels, and the comparison to current characterization techniques showed good correlation. This accessible technique, beyond contributing to the current 
meager literature of fatty acids as corrosion inhibitors, can also allow for the determination of acceptable benchmarks of corrosion, information that is sorely needed to efficiently steward global infrastructure. 


\section{Acknowledgements}

To my advisor, Dr. Tami Lasseter Clare, thank you for giving me a home in your lab at a time when I needed a place to be. I am grateful for your constant reassurance that it would all turn out okay, and that you pushed me so hard- I never would've found my way otherwise.

To my committee, I am grateful for your support, questions and suggestions throughout my time here at PSU.

To Dr. Natasja Swartz, your belief in me helped carry me through the first years of graduate school. I am entirely grateful that you helped me find dry land during the many times I was drowning, sometimes by necessary force.

To Katy Hosbein and Lyndsay Kissell, my twin pillars of support, I could not have asked for two more incredible women to be friends with- thank you for helping shape me into who I am. If anything, I want to be more like you.

To Dr. Eric Young, thank you for your constant questions and constant friendship.

I will always be grateful to Drs. Solanki and Padigi for originally giving me the idea and pushing me try out Prussian blue as a chemosensor.

To my brother, thank you for being a constantly understanding ear and cheerleader. Your opinion means the world to me. And to my mom, thank you for being an incredible inspiration and a support during the times I needed it most. I am so grateful for a family that reminds me that life is to be lived like the adventure it is. 
I have an army of other supporters to thank, including my past and present labmates, fellow students from other labs, undergraduates and mentees, as well as friends outside of graduate school who patiently listened and arranged helpful distractions for me. Thank you all.

I would also like to acknowledge the funding support for this project from the National Science Foundation CHE-1139230 and Portland State University.

Results from this work were presented or published in the following ways:

Price, C., Carroll, J., Clare, T.L. Multiresponsive hydrogel sensors for transition metal ions via Hofmeister series principles. $255^{\text {th }}$ National ACS Meeting - New Orleans, LA, March 2018.

Price, C., Carroll, J., Clare, T.L. Chemoresistive and photonic hydrogel sensors of transition metal ions via Hofmeister series principles. Sensors \& Actuators B. 2017, 256, 870-77.

Price, C., Carroll, J., Clare, T.L. Early detection of corrosion via spectroelectrochemical techniques. 71 ${ }^{\text {st }}$ ACS Northwest Regional Meeting - Anchorage, AK, Jul 2016.

Chapter 3 represents a manuscript in preparation. 


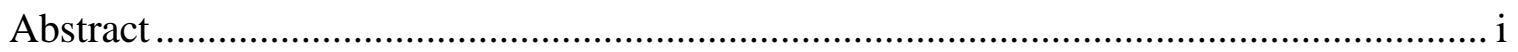

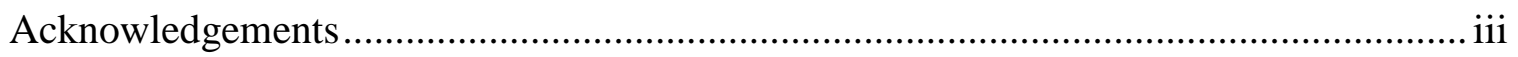

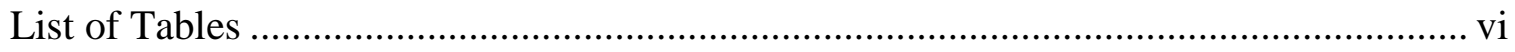

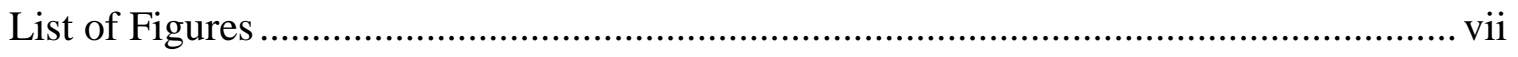

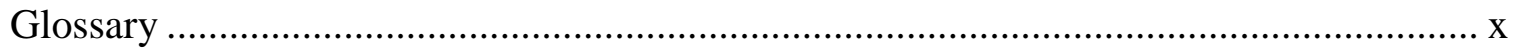

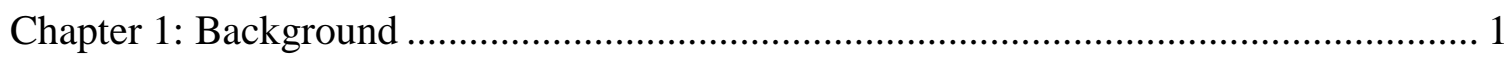

Chapter 2: Chemoresistive and photonic hydrogel sensors of transition metal ions via

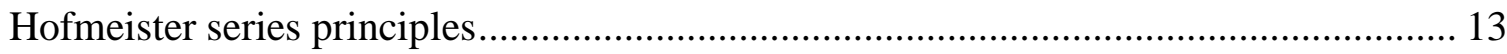

Chapter 3: Rapid quantitative photonic and impedimetric responses of hydrogel-based sensors for the in situ evaluation of corrosion inhibitors on steel................................. 37

Chapter 4: Conclusions \& Final Thoughts.................................................................. 54

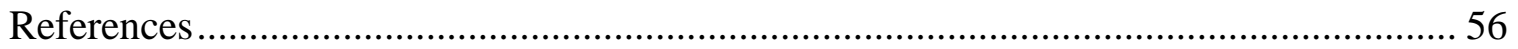

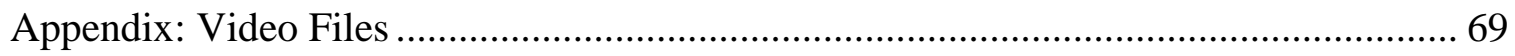




\section{List of Tables}

Table 2.1: List of transition metal ion solutions and the respective colors formed when combined with either $\mathrm{HCF}$ (III) (ferricyanide) or $\mathrm{HCF}$ (II) (ferrocyanide)...................... 34 


\section{List of Figures}

Figure 1.1: Depiction of the major processes of corrosion, beginning with zerovalent iron.

Figure 1.2: The polymeric headgroups of the hydrogels used in these studies. a) Depicts the structure of 2-acrylamido-2-methylpropane sulfonic acid (AMPS) and b) Depicts the structure of polyacrylic acid (PAA).

Figure 1.3: Volcano plot depicting the law of water affinities. CIP stands for "contact-ion pair", while SIP stands for "solvent-separated pair". The smaller spheres indicate kosmotropes, while the larger spheres indicate chaotropes.................................... 7

Figure 1.4: Structure of Prussian blue. 10

Figure 2.1: a) Photographs of the hydrogels from $0-170 \mathrm{ppm} \mathrm{Fe}^{2+}$, with reference dotted lines to aid in visualization of deswelling that occurs with increasing iron concentration. Gels at $0 \& 8$ ppm are outlined in red for clarity. b) Area averaged blue value calibration curve of hydrogels at various iron concentrations. c) Conductivity calibration curve of conductivity of hydrogels at various iron concentrations.

Figure 2.2: Deswelling calibration curves for varying $\mathrm{Cu}^{2+}$ or $\mathrm{Fe}^{2+}$ ion concentrations via formation of $\mathrm{Cu}-\mathrm{HCF}$ (III) or PB integrated hydrogels, respectively. Deswelling is defined as the ratio of the initial gel volume to the final gel volume at the given concentrations.

Figure 2.3: Decreasing Raman peak intensities with increasing PB concentration within the hydrogel. 28

Figure 2.4: Raman spectra of gels containing Prussian blue (blue trace), $\mathrm{Cu}-\mathrm{HCF}$ (III) (red trace), and a gel with no added metal ions denoted as "Bare gel" (broken lines). The inset shows a magnified view of the AMPS $\mathrm{SO}_{3}{ }^{-}$symmetric stretch for all three hydrogels. Spectra are normalized to the sulfonate peak.

Figure 2.5: Category plot of the conductivities of hydrogels equilibrated in various chloride electrolytes. Solid bars indicate conductivities of gels with electrolyte only; the patterned bars indicate the conductivities of the gels with Prussian blue formed within the hydrogel.

Figure 2.6: $3 \times 3 \mathrm{~cm}$ hydrogels exposed to various transition metal ions that produce different colored complexes upon addition of hexacyanoferrate. Swelling changes can be seen with varying (in gel) concentration. Gels with manganese ions are are shown on a gray background to increase contrast. The dashed lines correspond to $3 \times 3 \mathrm{~cm}$, and are shown to enable comparison of relative deswelling of the gels..... 
Figure 2.7: Raman spectra of gels containing Prussian blue and copper ferricyanide $(\mathrm{Cu}-$ $\mathrm{HCF}(\mathrm{III})$ ) and a gel without added complex, denoted as "Bare gel". Spectra are intensity normalized to the sulfonate peak at $1040 \mathrm{~cm}^{-1}$.

Figure 2.8: Raman spectra of gels containing copper ferricyanide ( $\mathrm{Cu}-\mathrm{HCF}(\mathrm{III}))$ and copper ferrocyanide $(\mathrm{Cu}-\mathrm{HCF}(\mathrm{II}))$ and a gel without added complex, denoted as "Bare gel". Spectra are intensity normalized to the sulfonate peak at $1040 \mathrm{~cm}^{-1}$.

Figure 3.1: a) Heat map of nanomoles of $\mathrm{Fe}^{2+}$ detected based on the calibrated colorimetric response for each of the inhibitors evaluated, where $n=$ the number of carbons in the inhibitor. Two controls were utilized; "solvent only" refers to a plate soaked in ethanol without inhibitor, while "freshly sanded" refers to a plate tested immediately after sanding. The solid blue line represents the average nanomoles of $\mathrm{Fe}^{2+}$ detected on substrates that had been prepared using corrosion inhibitor dissolved in ethanol alone, while the dashed line and squares indicate the same except the inhibitors were dissolved in a 4:1 mixture of ethanol and chloroform (required for solubility reasons), also indicated by asterisks in the legend. The horizontal diamond marker indicates the average for 'solvent' and the horizontal diamond marker indicates the average for 'freshly sanded'. b): Images showing the range of PB formation behavior. The increasing yellow coloration evident in the images moving to the right is due to unreacted ferricyanide remaining within the gel.

Figure 3.2: a) Steel plate with line scratched through a stearic acid film and into the metal. b) Image taken 30 min after gel was applied.

Figure 3.3: a) Representative impedance plots of corrosion inhibitors on steel. Green circles represent a plate tested immediately after sanding with no inhibitors added. Pink squares represent a plate modified with stearic acid. Closed markers are the impedance modulus spectra, while open markers are the phase angles. b) Equivalent circuit model used to fit all the EIS plots without added ferricyanide. $\mathrm{L}=$ inductor, $\mathrm{R}_{1}=$ solution resistance, $\mathrm{CPE}=$ constant phase element and $\mathrm{R}_{2}=$ charge transfer resistance. 48

Figure 3.4: Comparison of colorimetric trends with EIS CPE-P values and cutoff frequencies. Blue circle markers represent the average nanomoles of $\mathrm{Fe}^{2+}$ present, the green diamond markers are the plotted CPE-P values and the red square markers are the cutoff frequencies. The solid lines represent corrosion inhibitors that were dissolved in ethanol alone, while the dashed lines represent corrosion inhibitors that were dissolved in a 4:1 mixture of ethanol and chloroform. The disconnected diamond markers represent freshly sanded plates.

Figure 3.5: Comparison of \% decrease in CPE-P values for various treated panels. The \% change is based on difference between the types of hydrogels used: hydrogels pre-loaded with ferricyanide compared to those without. 50

Figure 3.6: a) Fe2 $\mathrm{p}_{3 / 2}$ portion of XPS plot of a steel plate modified with stearic acid. Solid trace is the spectrum, while the lighter dashed lines depict the peak fits. Peak at 
$706.64 \mathrm{eV}$ is assigned to $\mathrm{Fe}(0)$, peaks at $707.5 \mathrm{eV}$ and $708.27 \mathrm{eV}$ are assigned to $\mathrm{Fe}^{2+}$, while the peaks at $710.54 \mathrm{eV}$ and $713.47 \mathrm{eV}$ are assigned to $\mathrm{Fe}^{3+}$ and the satellite peak of $\mathrm{Fe}^{3+}$, respectively. b): Black circle markers indicate the expected intensity decrease ( $\mathrm{y}=$ 0.092), while red square and blue triangle markers indicate the normalized peak areas of $\mathrm{Fe}^{3+}\left(\mathrm{y}=-0.1486 \mathrm{x}, \mathrm{R}^{2}=0.865\right)$ and $\mathrm{Fe}^{2+}\left(\mathrm{y}=-0.1271 \mathrm{x}, \mathrm{R}^{2}=0.9618\right)$, respectively. The open markers indicate the values for formic acid, not used as part of the fit lines........... 52 


\section{Glossary}

Acrylamido-methylpropanesulfonic acid, one of the

AMPS

Bode plot

Chaotrope

Charge Transfer

Resistor $\left(\mathrm{R}_{\mathrm{ct}}\right)$

Constant Phase

Element (CPE)

Corrosion inhibitor

CPE-P polymeric units in the hydrogels and a highly acidic ion

exchanger.

A graph depicting the magnitude and phase response of a system over a range of frequencies.

A classification of an ion or headgroup as relatively large with a loosely held hydration sphere. See also: kosmotrope

The resistance associated with transferring charge from one phase to another, i.e. from electrode to solution.

An electrical equivalent circuit element used in place of a capacitor when the capacitor is imperfect, i.e. "leaky". See also: CPE-P

A substance added to a metal surface to mitigate corrosion.

The phase component of the CPE. When CPE-P $=1$, the phase is $-90^{\circ}$. Because a CPE is an imperfect capacitor, the CPE-P value must be below 1 . See also: constant phase element 
A hydrogel which has uptaken $\mathrm{Cu}^{2+}$ and formed a golden

$\mathrm{Cu}-\mathrm{HCF}(\mathrm{III})$-gel copper hexacyanoferrate complex. Exact formula of the complex is debated.

Cutoff Frequency Frequency where the kinetic energy of the charged species

$\left(v_{\text {cutoff }}\right) \quad$ begin to be attenuated.

Double Layer/ Layers of charged species at the solid-electrolyte interface.

Double Layer This separation of charges gives rise to a capactive

Capacitance $\left(\mathrm{C}_{\mathrm{dl}}\right) \quad$ component.

Electrochemical A technique that probes the dielectric properties of a surface

Impedance or material by measuring the impedance over range of

Spectroscopy (EIS) frequencies. See also: impedance

Headgroup

Hydrophilic end of a polymer not involved in polymeric network. Often contains one or more functional groups.

Impedance (Z) The ability of a system to oppose an alternating current.

Kosmotrope

A classification of an ion or headgroup as relatively small with a tightly held hydration sphere. See also: chaotrope

MBA

Methylenebis(acrylamide), the cross-linker that connects the polymers PAA and AMPS in the hydrogels. 
A hydrogel that has uptaken transition or lanthanide metal

M-HCF-gel

PAA

Prussian blue (PB)

PB-gel

PB-hydrogel

Raman

spectroscopy

Solution Resistance

X-ray

photoelectron spectroscopy (XPS)

Young's modulus ions and formed a metal hexacyanoferrate complex upon treatment with potassium ferri- or ferrocyanide.

Polyacrylic acid, one of the polymeric units in the hydrogels.

A dark blue metal hexacyanoferrate complex with the formula $\mathrm{Fe}_{4}(\mathrm{III})\left[\mathrm{Fe}(\mathrm{II})(\mathrm{CN})_{6}\right]_{3}$.

A hydrogel that has uptaken $\mathrm{Fe}^{2+}$ ions and formed Prussian blue within upon treatment with potassium ferricyanide.

A technique which provides information on the type of bonds present in a material by exciting electrons and measuring the inelastically scattered light.

The opposition to current flow between the counter and reference electrodes.

A technique that bombards a surface with X-rays and measures the energy of the emitted photoelectrons in order to obtain a spectrum of the elements present and their chemical and electronic states.

A measure of stiffness. A material with a high modulus can withstand more uniaxial stress before deforming. 


\section{Chapter 1: Background}

\subsection{Briefly Defining the Problem of Corrosion}

Corrosion processes are insidious, referred to by the Pentagon as "the pervasive menace" [1]. If necessary preventive measures and inspections are neglected, these processes can be something akin to a force of nature, leading to such tragedies as Flint, Michigan, the Sinopec oil pipeline explosion, and the post-earthquake leak at Fukushima's nuclear power plant, among others. Even without such dramatic events, corrosion is a degrading force that must be constantly battled: for this reason, the pricetag of worldwide corrosion in 2016 was $\$ 2.505$ trillion U.S. dollars, or 3.4\% of the world gross national product [2].

For the purposes of this document, metal refers to a transition metal that has been refined to zerovalent so as to achieve the favorable characteristics of maleability, strength, ductility, luster, and electrical and thermal conductivity. This process requires extensive energy input, so, from a thermodynamic standpoint, it is energetically favorable to oxidatively return to more chemically stable forms. Corrosion is defined here as the reactions of the metal as it interacts with its environment.

Alloys of iron, particularly steel, are relied upon in construction and similar applications due to their relatively low cost and high strength-to-weight ratio. As such, they can be considered the most relevant metals in today's global economy. The positive attributes of iron-carbon alloys are offset by generally poor corrosion resistance, primarily due to the lack of an effective passivation layer [3-5]. While there are various 
strategies used to slow the processes of corrosion, among them cathodic protection and organic coatings, over time these will all lose effectiveness. The focus of this body of work is in developing cost-effective, practical strategies for detecting the earliest stages of corrosion, when the preventive measures are beginning to lose their protective quality.

\subsection{Corrosion of Iron}

The "final" products of ferrous corrosion are a conglomeration of different iron oxide and hydroxide species, depending on the environmental pollutants present, the temperature/humidity cycles, the exact alloy used, and so forth, and is an ongoing topic of research [5]. However, it is well understood that the first anodic reaction to alter the state of zerovalent iron would be oxidation to divalent iron (Eq. 1.1), accompanied by the corresponding cathodic reaction of the electrons with oxygen.

$$
\mathrm{Fe}^{0} \rightarrow \mathrm{Fe}^{2+}(\mathrm{aq})+2 \mathrm{e}^{-}
$$

If unhalted, $\mathrm{Fe}^{2+}$ can then form insoluble hydroxides, or further oxidize to $\mathrm{Fe}^{3+}$, which would form other insoluble hydroxide species. Under certain conditions, these species can dehydrate to form mixed iron oxide species that can be loosely assigned as $\mathrm{Fe}_{2} \mathrm{O}_{3}$ or $\mathrm{Fe}_{3} \mathrm{O}_{4}$, as depicted in Figure 1.1. These hydroxide and oxide species damage structural integrity by forming non-passivating, loose, porous layers that are referred to in the vernacular as "rust". The thermodynamics of these species are extremely favorable: for example, Gibbs free energy for the formation of $\mathrm{Fe}_{2} \mathrm{O}_{3}$ is $-742.2 \mathrm{~kJ} / \mathrm{mol}$, while the $\mathrm{Ksp}$ is $1.12 \times 10^{-88}$ under standard conditions. These insoluble corrosion products mark the 


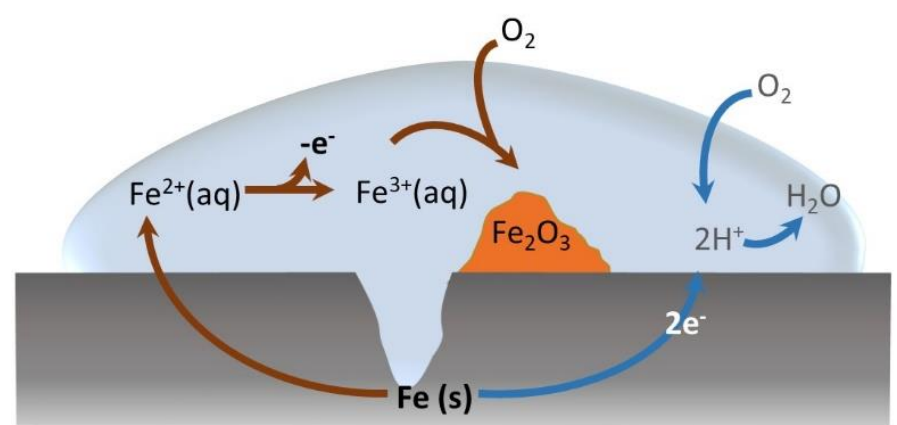

Figure 1.1: Depiction of the major processes of corrosion, beginning with zerovalent iron.

practical end of reversibility, in contrast to the initial species of $\mathrm{Fe}^{2+}$ and $\mathrm{Fe}^{3+}$, which can be considered highly soluble. As such, this body of work is focused on the detection of these initial soluble ions, for iron and other relevant engineering metals. This is referred to as early detection, or detection at a stage where it is still feasible to intervene and prevent more advanced species of corrosion. In this way, maintenance personnel would have the ability to make well-informed decisions about whether or not treatment is necessary, potentially saving time, money \& labor, as well as allowing for greater freedom in choice of protective coating for aesthetic, cost or environmental reasons. Chapter 2 characterizes and presents the theoretical background for a spectroelectrochemical sensor able to quantify sub-ppm amounts of the initial soluble ions relevant for iron and copper-based metals, with the same methodology demonstrating success for nine other metallic elements used as alloying elements or protective coating components. Chapter 3 demonstrates the ability of the sensor to directly detect and quantify ions as they solubilize on the surface of a metallic substrate, an ability which enables the future determination of acceptable quantitative benchmarks of corrosion. 


\subsection{Current State of the Field of Corrosion Detection}

There are some requirements in building a corrosion sensor; ideally it should be non-destructive, easy to interpret, field-capable, inexpensive, quantitative and specific. Much of the current literature on in situ corrosion detection focuses on the detection of physical degradation of the metal due to advanced processes of corrosion, such as stress fractures, changes in metal thickness, etc. Commonly used techniques are ultrasonic or acoustic imaging [6-12], electromagnetic techniques [13-18], electrical resistance [19-22] or electrochemical noise [23-26]. Some Infrared/thermal or Terahertz imaging techniques have been attempted [27-33]; however such techniques are cost-prohibitive and not always reliable. It is clear that, while these techniques have their use in certain situations, they are limited to detecting damage that has already occurred, and are not able to provide information on the state of a metal surface prior to sustaining damage.

The limited number of studies that have focused on detection of the chemical, as opposed to physical, alterations to corroding metal have primarily ultilized changing $\mathrm{pH}$ as the analyte [34-39], while using fluorometric probes as the indicator. To the author's knowledge, there have been only three qualitative studies of corrosion-induced ions, two of $\mathrm{Al}^{3+}$, utilizing fiber optic probes $[35,40]$, and one of $\mathrm{Fe}^{3+}$, utilizing a polyvinyl alcohol film [41]. Some studies have proposed using fluorometric sensors embedded in protective coatings [42-44], which is not ideal, as it restricts the coating formulations that can be used, and does not address the corrosion of previously manufactured structures. 
It should be noted that while the advanced techniques presented above are present in the literature, probably the most common "detection" techniques in practice by structural engineers involve removing a portion of the coating in order to test adhesion (e.g. ASTM D4541-17 \& ASTM D2197-16) [45, 46]. This is obviously not ideal, as it is destructive and provides limited information. This illustrates the need for an inexpensive corrosion detection technique that can be easily instituted by those charged with the care and construction of the world's buildings, bridges, sculptures, airplanes, ships, and so forth. In this work it was found that squares of hydrogel could be applied to metal substrates to measure the amount of soluble ions on the surface, an inexpensive, robust and accessible technique, covered in Chapter 3.

\subsection{Hydrogel-based Sensors}

The logistics of constructing a field-deployable corrosion sensor would dictate moving away from solution-based sensors, which are difficult to apply to vertical or curved surfaces. Flexible and self-contained hydrogel-based sensors are an attractive answer, and have demonstrated a wide range of different sensing mechanisms: changes in optical properties [47-49], mass and volume [47, 50-52], electrical properties [53-55], and/or redox chemistry [56-58]. Hydrogels often demonstrate multisignaling, most often as "smart" behavior, where a physical response to an analyte can render other measureable chemical change(s) $[47,52,59-66]$. The hydrogels used in this work demonstrated changes in conductivity and swelling due to the uptake of transition metal ions and subsequent formation of a complex, which also altered the hydrogel's optical properties, as is demonstrated in Chapter 2. These electrical and optical signals were 
leveraged in Chapter 3 to characterize the corrosion processes occuring on steel surfaces modified by fatty acid corrosion inhibitors.

These sensing capabilities are primarily driven by the hydrogel's polymer headgroups and their interactions with the analyte(s). Because there are many different types of headgroups available [67-71], it is possible to tune a hydrogel's sensing capabilities for particular analytes. In this work, the hydrogels used were co-polymers of acrylamido-methylpropane sulfonic acid (AMPS) and polyacrylic acid (PAA), depicted in Figure 1.2, and cross-linked by methylene bis-acrylamide. The affinity of the AMPS sulfonic acid headgroups were utilized to form associations of sufficient intensity to alter the electrical, mechanical and optical properties of the hydrogels, as characterized in Chapter 2. Because of the capacity of the gels to bind ions, such devices often serve to collect and pre-concentrate analytes as well, offering an improvement in detection limit and/or sensitivity over solution-based sensors [72-74], something which is also demonstrated in Chapter 2.

a)

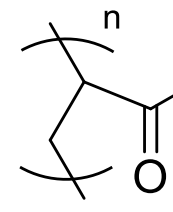

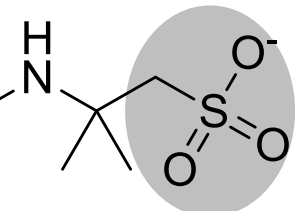

b)

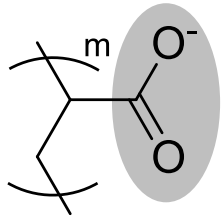

Figure 1.2: The polymeric headgroups of the hydrogels used in these studies. a) Depicts the structure of 2-acrylamido-2-methylpropane sulfonic acid (AMPS) and b) Depicts the structure of polyacrylic acid (PAA).

Covalently bound hydrogels, such as those used in this project, allow greater freedom in choosing experimental parameters. For instance, the covalently bound nature of these hydrogels allowed for equilibration in a number of electrolyte solutions, buffers and solvents, based on the specific need of the situation. The chemical and mechanical 
properties of such hydrogels can also be tuned by changing the proportions of the monomers and/or cross-linker to allow for specified application $[66,75,76]$. In Chapter 2, an increase in the sensitivity of the sensor is demonstrated with an increase in the AMPS concentration of the hydrogel.

\subsection{Interaction(s) of an Ion with a Hydrogel}

The introduction of an analyte (here, transition metal ions) into a hydrogel affect its architecture and subsequently the signal(s) produced. In order to understand and predict these phenomena, it is necessary to understand the major principles that determine the quality of headgroup interactions with ions. It was first noted by Franz Hofmeister that the capability of ions to salt out proteins seemed to be related to their hydration capabilities [77, 78]. In 2006, Collins, et.al [79, 80], suggested the "law of matching water affinities", which states that ions with similar affinities for water form closer

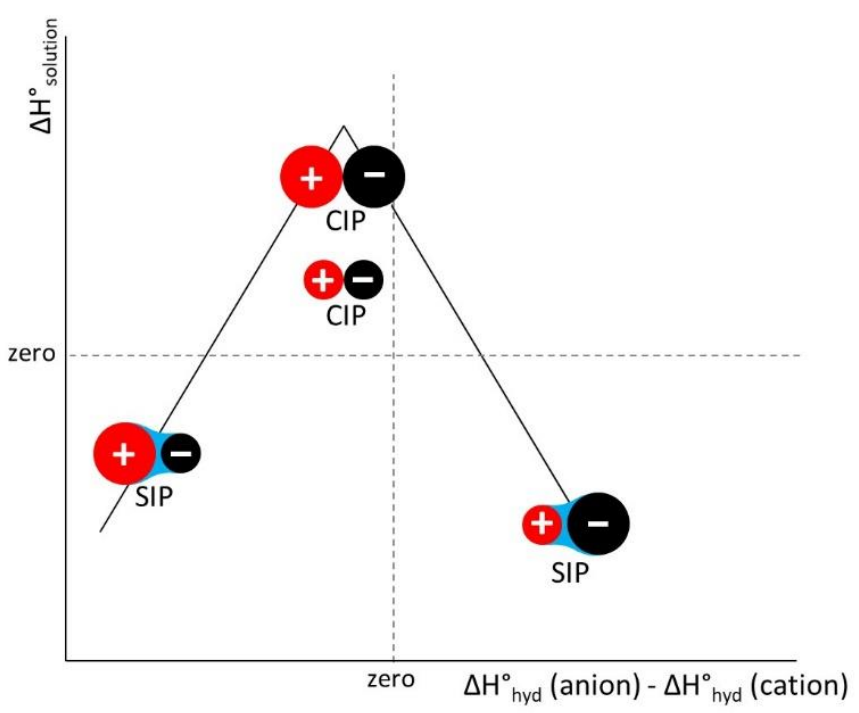

Figure 1.3: Volcano plot depicting the law of water affinities. CIP stands for "contact-ion pair", while SIP stands for "solvent-separated pair". The smaller spheres indicate kosmotropes, while the larger spheres indicate chaotropes. 
associations with each other. Figure 1.3 graphically depicts this rule; similarly sized ions energetically prefer to form contact-ion pairs, as the point charges are better able to approach each other. In contrast, dissimilar ion sizes prefer to retain solvent layers, as the point charges are better able to approach mid-sized water molecules [80]. It should be noted that, as shown in Figure 1.3, ions are sorted into two categories based on their charge density and hydration energies: chaotropes or kosmotropes, where kosmotropes are smaller ions that have tightly held hydration spheres, and chaotropes the inverse, although inevitably there are varying degrees of these two classifications [81]. For monovalent cations, this shift between strongly to weakly hydrated occurs at approximately the radius of a sodium ion, which has a charge/size ratio of 9.35 [82]. These principles have been shown to extend to polyelectrolytes [82-86], which is relevant when considering the interactions of hydrogel headgroups with metal ions. In Chapter 2, the sulfonic acid headgroup, a highly acidic ion exchanger, was found to interact most strongly with the metal ions of interest. The variation in intensity of interaction with the different ions correlated with the known categorization of sulfonic acid as a chaotrope [79].

The mere introduction of counterions into a charged hydrogel network mitigates the repulsive forces between polymer headgroups and therefore induces reductive volumetric changes [87]. Beyond this effect, ionic cross-linking, or the linking of two or more charged polymer headgroups via multivalent ions, can induce significant volumetric and mechanical changes [88-90]. The exact nature of the bonding is affected by the types of divalent ions present; alkali earth ions remain as noncovalent bonding, while transition 
metal ions tend towards forming stronger complexes, while some rare-earth metals have shown practically irreversible behavior [87, 88]. Measurable variations of the behavior along series of alkali earth and transition metal ions have been observed [87-89]. The effects of ionic cross-linking were observed in the increasing de-swelling of hydrogels, as increasing amounts of divalent metal ions were introduced, recorded in Chapter 2.

The types of ions present within the hydrogel can also affect the hydrogen bonding and viscosity of water. The names chaotropes and kosmotropes mean "disordermaker" and "order-maker", respectively, and refer to the ways in which the ions affect the hydrogen bonding of water. Chaotropes, with polarities greater than that of water, discourage the formation of hydrogen bonding, and can increase the density of water. Kosmotropes, with polarities close to or less than that of water, either encourage or do not affect the hydrogen bonding of water $[82,83]$. With a change in the hydrogen bonding of the water within a hydrogel, a change in the electrical properties of the hydrogel can be expected [91]; the conductivity changes in the hydrogel sensors throughout this work are partially attributed to this.

\subsection{Prussian Blue as an Amplificatory Probe}

While hydrogels have standalone sensing capabilities, it is beneficial to add in a secondary probe that works in tandem to increase the signal-to-noise ratio. One such type of probe are metal hexacyanoferrate complexes, which have exhibited changes in both electrical and colorimetric properties upon complexation [92-94]. These complexes

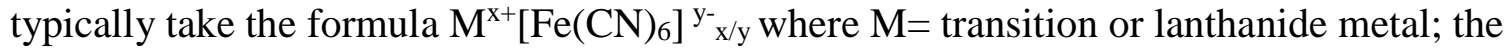
most well-known of these compounds is Prussian blue, formed when $\mathrm{Fe}^{2+}$ or $\mathrm{Fe}^{3+}$ ions are 
reacted with ferricyanide $\left[\mathrm{Fe}(\mathrm{CN})_{6}\right]^{3-}$ or ferrocyanide $\left[\mathrm{Fe}(\mathrm{CN})_{6}\right]^{4-}$, respectively to form colloid [95]. Prussian blue forms a face-centered cubic lattice, with low spin $\mathrm{Fe}^{2+}$ connected to the carbon of the cyanide bridges, and high spin $\mathrm{Fe}^{3+}$ connected to the nitrogen, depicted in Figure 1.4; one quarter of the $\left[\mathrm{Fe}\left(\mathrm{CN}_{6}\right]^{4-}\right.$ units are replaced by water

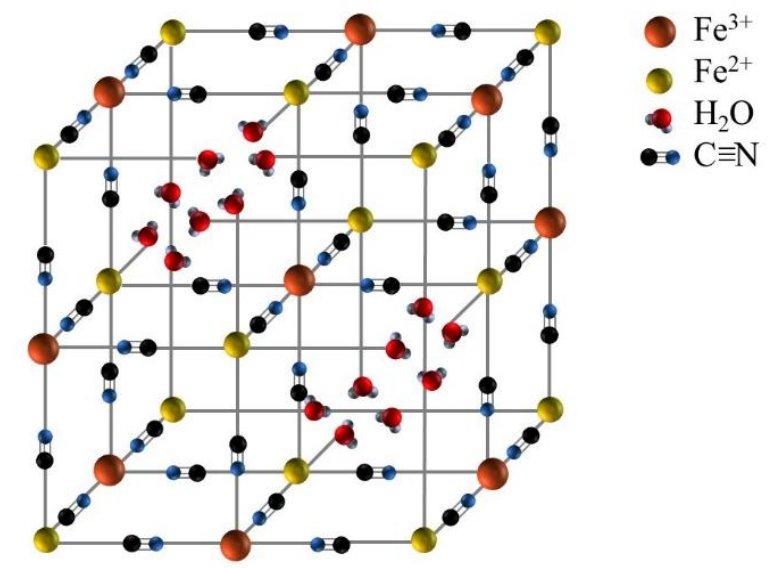

Figure 1.4: Structure of Prussian blue.

[96-98]. The blue color originates from an intervalence charge transfer between the $\mathrm{t}_{2 \mathrm{~g}}$ orbital of the carbon and the $t_{2 g}$ orbital of the nitrogen [99-101].

Previous to this work, colorimetric and electrical changes have only been demonstrated in solution; in this body of work both phenomena showed measureable correlations with ion concentration within the hydrogels. Because the hydrogel headgroups bind to the transition metal ions, there is some evidence, as presented in Chapter 3, that the color formation can quickly visually demonstrate localized damage or film defects, a valuable trait for an in situ sensor. Divalent iron and copper complexes were the most extensively investigated here, but thirteen total metal ions were reacted with either or both $\left.\mathrm{Fe}(\mathrm{CN})_{6}\right]^{3-}$ or $\left[\mathrm{Fe}(\mathrm{CN})_{6}\right]^{4-}$ in solution, for a total of 27 unique combinations, many of which had unique spectral properties. This valuable set of data, not seen before in the literature, is recorded in Chapter 2. Nine of those combinations 
(beyond $\mathrm{Fe}^{2+}$ and $\mathrm{Cu}^{2+}$ ) displayed particularly unique colors; they were tested and found to successfully form within hydrogels.

\subsection{Scope of Work}

This body of work contributes a hydrogel based sensor for the detection of transition metal ions from both solution and/or solid substrates. Chapter 2 details the multiple signals produced by metal hexacyanoferrate-hydrogels in response to transition metal ions, specifically conductivity, color, volumetric and vibrational changes. In particular the colorimetric and electrical changes demonstrated several orders of magnitude in range and are both easily translatable to fieldwork. Beyond demonstrating their capabilities as a sensor, the hydrogels were studied by Raman and impedance spectroscopies to interpret the signals in light of the appropriate thermodynamic principles. This understanding allows the sensors to be judiciously designed for improved specificity, signal-to-noise ratio, and so forth.

Chapter 3 presents a practical application of the hydrogel sensor for detection of ions from metal substrates, specifically, those treated with fatty acids in a range of chain lengths, serving as corrosion inhibitors. The literature on fatty acids as corrosion inhibitors is lacking, so this study served the dual purposes of confirming the efficacy of the sensors and of the fatty acid treatments. Colorimetric data, which was gathered through the accessible technique of digital photography, correlated nicely with results from the established techniques of X-ray photoelectron and electrochemical impedance (EIS) spectroscopies. The hydrogels also demonstrated changes in their impedance characteristics that could be exploited as a second detection technique. The colorimetric 
data yielded quantitative results, something that will be beneficial to corrosion experts working to establish benchmarks for corrosion management. 
Chapter 2: Chemoresistive and photonic hydrogel sensors of transition metal ions via Hofmeister series principles

Reprinted from Sensors \& Actuators B, 256, Price, C., Carroll, J., \& Clare, T.L. Chemoresistive and photonic hydrogel sensors of transition metal ions via Hofmeister series principles, 870-77, 2017, with permission from Elsevier.

Abstract

We evaluate the sensory response of hydrogels composed of polyacrylic acid (PAA) co-polymerized with acrylamido-methyl propane sulfonic acid (AMPS) exposed to eleven different transition metal ions, which was reacted with hexacyanoferrate ions. Trends in the chemoresistive responses of the gels to ions of $\mathrm{Cu}^{2+}, \mathrm{Fe}^{2+}, \mathrm{Mn}^{2+}, \mathrm{Ni}^{2+}, \mathrm{Pb}^{2+}$, $\mathrm{Co}^{2+}, \mathrm{Sn}^{2+}, \mathrm{Cd}^{2+}, \mathrm{Zn}^{2+}, \mathrm{Mo}^{5+}$, and $\mathrm{Ag}^{+}$due to the formation of metal hexacyanoferrate complex are shown to depend upon the strength of the gel headgroup-ion interactions based on the Hofmeister series and confirmed using Raman spectroscopy. These hydrogels either showed a decrease in resistivity and swelling with increasing ion concentration or the opposite effect. Sensitivity by colorimetric and conductivity measurements was approximately $100 \mathrm{ppb}$, which can be adjusted by the gel's dimensions and density of headgroups within the gel. The photonic and vibrational characteristics of the gels upon ion addition were investigated for use in spectroelectrochemical sensing devices by imaging, electrochemical impedance spectroscopy and Raman spectroscopy. 


\section{Introduction}

The ability of sorbent materials to collect analytes is closely tied to performance characteristics in sensors, responsive materials and analyte-delivery systems across a wide range of fields including biomedicine, corrosion science and environmental monitoring [73, 102-105]. Hydrogels have been employed in many such devices because of their attractive characteristics, a list which includes their compositional variability, tunable mechanical properties, electrolyte exchangeability, sensitivity to stimuli, low electrical impedance, portability and low cost $[75,106]$. Headgroups of hydrogels include carboxylic acids, ammonium, sulfonates, amides, amines and hydroxyls, which can all be leveraged to effectively absorb and concentrate metal ions from solution [67-71], allowing for detection limits in the sub-ppm range. Common device responses are generated by analyte-headgroup interactions that act to swell or deswell the hydrogel [52, $63,66,107,108]$, while others involve an added marker in the form of a fluorescent dye, nanoparticle or colorimetric tag which then gives a measurable spectral change of the gel in response to analyte concentration [59, 64, 65, 109-112]. Still others use electrical changes within hydrogels from altered resistance, capacitance, impedance or voltammetry [53-55]. Because the various responses of hydrogels to analytes are usually correlated, often multiple signals are produced [54, 107]; and, as multi-responsive materials, hydrogels are of great interest in dual-functional devices, such as spectroelectrochemical devices $[48,103]$.

Detection of metal ion analytes enables important research questions to be addressed in many fields, including biosensing, environmental monitoring and corrosion 
science $[35,113,114]$. The ability to determine the concentration of transition metal ions present in the human body, a body of water, in the air or on a potentially corroding metal surface is a necessity in order to make informed decisions and treatment plans. In the case of corrosion of steel and copper alloys, detection of small amounts of $\mathrm{Fe}^{2+}, \mathrm{Fe}^{3+}, \mathrm{Cu}^{+}$and $\mathrm{Cu}^{2+}$ could permit the development of an early corrosion warning system, capable of signaling the failure of anti-corrosion measures such as protective coatings or cathodic protection. In the case of environmental analysis, real-time monitoring of heavy metal ions, such as $\mathrm{As}^{3+}, \mathrm{Cd}^{2+}, \mathrm{Cr}^{3+}, \mathrm{Pb}^{2+}$ or $\mathrm{Hg}^{2+}$, which are considered to be of highest significance to health [115], could warn if a factory, agricultural practice, etc., presents a risk to the public and/or environment.

The formation of Prussian blue (PB), the blue pigmented complex $\mathrm{Fe}_{4}(\mathrm{III})\left[\mathrm{Fe}(\mathrm{II})(\mathrm{CN})_{6}\right]_{3}[99]$, has been used to detect $\mathrm{Fe}^{2+}$ or $\mathrm{Fe}^{3+}$ in solution when salts of ferricyanide $\left[\mathrm{Fe}(\mathrm{CN})_{6}\right]^{3-}$, or ferrocyanide $\left[\mathrm{Fe}(\mathrm{CN})_{6}\right]^{4-}$, respectively, are used [95]. Complexes of other transition and lanthanide metal ions (e.g. $\mathrm{Cu}^{2+}[116], \mathrm{Ti}^{4+}[117], \mathrm{Cr}^{3+}$ [118], $\mathrm{Sn}^{4+}, \mathrm{Al}^{3+}, \mathrm{Mn}^{2+}, \mathrm{Zn}^{2+}[93], \mathrm{Co}^{2+}, \mathrm{Ni}^{2+}, \mathrm{Pd}^{2+}, \mathrm{In}^{3+}[92], \mathrm{Ga}^{2+}[119], \mathrm{Y}^{3+}$ [120], $\mathrm{Zr}^{4+}$ [121], $\mathrm{Ag}^{+}[122], \mathrm{Cd}^{2+}[123], \mathrm{La}^{3+}[124], \mathrm{Pb}^{2+}[125], \mathrm{Pt}^{2+}[126]$, and $\mathrm{Bi}^{3+}$ [127]) may be also be formed with salts of ferricyanide or ferrocyanide, having the general formula of $\mathrm{M}^{\mathrm{x}+}\left[\mathrm{Fe}(\mathrm{CN})_{6}\right]^{\mathrm{y}-}{ }_{\mathrm{x} / \mathrm{y}}$ where $\mathrm{M}=$ transition metal, $[92,116]$ and have found potential application in sensors, environmental remediation, imaging, and energy conversion [92, 117-119, 122]. Both hexacyanoferrate ions and metal hexacyanoferrate complexes have been characterized by impedance spectroscopy in solution [92, 94, 128-132] and the unique colors of the complexes allow for spectral differentiation of the metal ions present 
[93, 133]. Given that Prussian blue and its metal hexacyanoferrate analogues can be formed in aqueous solution, we hypothesize that it is likely that such complexes can also be formed within hydrogels and used in transition metal ion sensing applications by colorimetric, electrical and mechanical/volumetric changes.

The electrical and mechanical changes that may occur within hydrogels upon formation of metal hexacyanoferrates are influenced by the thermodynamic principles that drive interactions between cations and headgroups. It is known that the introduction of divalent, rather than monovalent, cations into already existing anionic hydrogel networks causes an increase in Young's modulus. This increase is taken to indicate headgroup-cation interactions that have formed a secondary "ionically cross-linked" network, in addition to the primary covalently bonded network of the hydrogel. The type of multivalent cation involved determines the level of interaction; alkali earth cation interactions typically consist of electrostatic interactions, while interactions with transition metal cations tend towards quasi-covalent bonds [88-90].

Consideration of the "law of matching water affinities" is relevant in the discussion of possible headgroup-cation interactions and their intensities of association. First proposed by Collins in 2006, this law states that ions of similar size have similar enthalpies of hydration, making them more likely to form close ion pairs than ions of dissimilar sizes [79]. This law was developed from initial observations by Hofmeister and has been extensively observed by others $[77,78,134,135]$. These principles can be extended to polyelectrolytes, where, for example, a sulfonic acid headgroup is considered to be chaotropic because it is more likely to form close ion pairs with large, weakly 
hydrated ions [83, 84, 136, 137]. Considering the equation for conductivity:

$$
\sigma=n \mu Z
$$

where $\sigma$ is conductivity, $\mathrm{n}$ is number of charge carriers, $\mu$ is the mobility of the charge carriers, and $\mathrm{Z}$ is the charge of those carriers, it is possible to see that the mobility parameter will be altered by the degree of association between the headgroup and cation. The associative response of hydrogels to soluble transition metal ions, in turn, affects the viscosity of water contained within the hydrogel. Viscosity of different aqueous salt solutions is dependent upon the hydration free energy and the hydrated radius of the cation, as summarized by Tansel [82]. A strong hydration shell causes more resistance to flow, and an increased viscosity of water. These types of ions are often categorized as kosmotropic, which have a polarity greater than that of water and thus their presence encourages hydrogen bonding between water molecules [82, 83]. It is expected that the changing viscosity of the water as different types of ions are introduced would also stimulate changes in the impedance of the hydrogels.

In this study, hydrogels composed of polyacrylic acid (PAA) co-polymerized with acrylamido-methyl propane sulfonic acid (AMPS) were exposed to soluble transition metal ions. PAA is known to have a strong proton affinity, so AMPS is likely the primary ion exchanger in this case $[85,86]$. After exposure to transition metal ions, the hydrogels were treated with ferricyanide or ferrocyanide to form Prussian blue or one of its metal hexacyanoferrate analogues. The formation of this complex affected the impedance of the hydrogels, and the unique colors of the complexes allowed for differentiation of the metal ions present. An advantage of our method is the robust nature of the impedimetric 
detection; there is no need for a marker or tag that could become photobleached or lose sensitivity over time. In order to measure the concentration of metal ion present, it is only necessary to measure the impedance at one frequency, allowing for a rapid measurement with simple data interpretation. These hydrogels have already been utilized to assess the protective quality of coatings on coated outdoor metalworks (e.g. sculptures) using impedance spectroscopy, demonstrating its ability to be used as a portable sensor [138]. In this work, we expand the role of such hydrogels to act not only as the solid electrolyte in an impedimetric sensing device, but to collect and have an active response to transition metal ions, which are markers of active corrosion.

\section{Experimental}

\subsection{Hydrogel Synthesis}

All chemicals for hydrogel synthesis were obtained from Sigma-Aldrich and solutions were made using deionized $\mathrm{H}_{2} \mathrm{O}$. AMPS-co-PAA hydrogels were synthesized from the sodium salts of 2-acrylamido-2-methylpropanesulfonic acid (AMPS; $50 \mathrm{wt} \%$ solution) and poly(acrylic acid) (PAA; average MW 5100, $50 \mathrm{wt} \%$ solution). N,N'methylenebis(acrylamide) (MBA; $1 \mathrm{wt} \%$ solution) was used as the cross-linker and the polymerization was carried out via the potassium persulfate and metabisulfite redox initiator system (1 wt \% solutions) with glycerol added as a humectant. Further details on the hydrogel synthesis are available in a previously published paper [138].

Once synthesized, the hydrogels were removed from their molds and allowed to equilibrate with the desired supporting electrolyte for two hours at minimum, and then 
the electrolyte was replaced with fresh solution and the hydrogels again equilibrated for two hours. This process also allowed for removal of unreacted monomers. The typical hydrogel thickness after equilibration was $3.0 \pm 0.2 \mathrm{~mm}$.

The various supporting electrolytes used were sodium chloride (Fisher Chemical), cesium chloride (Amresco ultra pure), rubidium chloride (Alfa Aesar 99.9\%) strontium, magnesium, potassium and calcium chloride (Sigma-Aldrich 99\%) and were prepared in deionized $\mathrm{H}_{2} \mathrm{O}$ at a concentration of $10 \mathrm{mM}$ with a $\mathrm{pH}$ of 4 . The $\mathrm{pH}$ was adjusted with 1 M hydrochloric acid as necessary, measured with an Oakton Ion 510 Series meter.

\subsection{Synthesis of Prussian Blue and Analogs in Hydrogels}

All reagents were used as received without further purification. To prepare Prussian blue or one of the other transition metal ion complex analogs within the hydrogels, $3 \mathrm{~cm} \times 3 \mathrm{~cm}$ portions of hydrogel, already equilibrated in supporting electrolyte as described above, were placed into appropriately sized beakers. Then a $\mu \mathrm{L}-$ $\mathrm{mL}$ sized aliquot of the desired metal salt stock solution (depending on the desired final concentration) was added to the beaker, as well as the amount of deionized water needed to bring the total $\mathrm{mL}$ of the metal ion solution and water to $10 \mathrm{~mL}$. Then $90 \mathrm{~mL}$ of $10 \mathrm{mM} \mathrm{NaCl}$ at $\mathrm{pH} 4$ (unless otherwise noted) was added so that the total final volume the gels were soaked in was $100 \mathrm{~mL}$. The beakers were then covered and the gels soaked for 8-12 hrs. The hydrogels were then removed from the beakers, placed on glass, excess electrolyte wicked off, and a $375 \mu \mathrm{L}$ aliquot of the appropriate hexacyanoferrate ion was pipetted evenly over the hydrogel forming a droplet that evenly covered the gels and 
allowed to rest for $30 \mathrm{~min}$, which was a sufficient time for the entire droplet to be absorbed into the gel and for the complex to form. The concentration of the hexacyanoferrate ion was kept at approximately $1.25 \times$ the stoichiometric equivalent needed to form the complex (i.e. the transition metal ions were the limiting reactant). It should be noted that one exception to this procedure are the gels in Figure 2.6, which were soaked in a total final volume of $10 \mathrm{~mL}$, rather than $100 \mathrm{~mL}$. Solutions of potassium ferricyanide (Acros Organics 99+\%) or potassium ferrocyanide (J.T. Baker Chemical) were made with deionized $\mathrm{H}_{2} \mathrm{O}$, purged with nitrogen, and then stored in the dark. Solutions of iron ammonium sulfate (Sigma Aldrich 99\%) were the source of $\mathrm{Fe}^{2+}$ ions, while chloride salts of $\mathrm{Ni}^{2+}$ (Mallinckrodt), $\mathrm{Mn}^{2+}$ (Merck), $\mathrm{Cu}^{2+}$ and $\mathrm{Co}^{2+}$ (Alfa Aesar) were the sources of the other transition metal ions.

\subsection{Synthesis of Aqueous Solutions of Prussian Blue and Analogs}

The color observations presented in Table S1 were prepared as follows. A 550 ppm solution of the respective metal salts were made and ferricyanide or ferrocyanide was added to be stoichiometrically equivalent. Color changes (or the lack thereof) were observed and recorded. Chloride salts of $\mathrm{Al}^{3+}, \mathrm{Pb}^{2+}, \mathrm{Ni}^{2+}$ (Mallinckrodt), $\mathrm{Cd}^{2+}$ (J.T

Baker), $\mathrm{Zn}^{2+}$ (Fisher Science Education), $\mathrm{Sn}^{2+}, \mathrm{Mo}^{5+}, \mathrm{Co}^{2+}, \mathrm{Cu}^{2+}$ (Alfa Aesar), $\mathrm{Zr}^{2+}, \mathrm{Cr}^{3+}$ (Sigma Aldrich), $\mathrm{Mn}^{2+}$ (Merck) and an acetate salt of $\mathrm{Ag}^{+}($Matheson Coleman + Bell 99.5\%) were used as the sources of the metal ions.

\subsection{Colorimetric Analysis}

Images were taken with a Nikon D3100 SLR camera in a custom lightbox with 
full spectrum lighting at f/10 with an ISO of 400. Any unreacted ferricyanide was removed from the gels by rinsing them in fresh electrolyte prior to photographing. ImageJ 1.50i software was used to obtain the average blue value and its standard deviation from each hydrogel's image area. The color value reported was obtained by subtracting the ImageJ blue value from 256 to obtain a positive slope in the calibration plot. Files shot in RAW were compared to the ProPhoto RGB and sRGB equivalents and less than a $1 \%$ difference in the blue values throughout the entire concentration range was observed. JPEG files in sRGB color space were used for the final analysis.

\subsection{Impedance Spectroscopy}

Impedance measurements over a frequency range of $1 \mathrm{MHz}-0.1 \mathrm{~Hz}$ were completed using a Gamry REF600 with Echem Analyst software to process the data. The potential applied was $20 \mathrm{mV}$ AC versus the open circuit potential. The gels were clamped between two silver plates (Alfa Aesar) acting as the counter and working electrodes, respectively, with a Teflon spacer to control the amount of pressure exerted on the hydrogel. Conductivity was calculated by choosing a frequency where the phase angle was zero, meaning the Bode plot was entirely resistive at that frequency, which was $20.02 \mathrm{kHz}$. The resistance value was normalized to the exact area of the gel by dividing by a calculated cell constant $\left(\mathrm{K}_{\text {cell }}\right)$, as shown in Equations $2 \& 3$.

$\mathrm{K}_{\mathrm{cell}}=1 / \mathrm{gel}$ area

Normalized $\mathrm{R}=\mathrm{R} / \mathrm{K}_{\text {cell }}$ 
Equation 4 was used to convert resistance to conductivity. It should be noted that the data shown in Figures $2.1 \mathrm{~b} \& \mathrm{c}$ is the result of three data sets, taken on different days and merged together.

$$
\sigma=1 / \rho
$$

\subsection{Swelling Characterization}

Throughout the study concentrations are presented as the final concentration within the hydrogel, reported in ppm. The volume of the hydrogels were calculated after the transition metal ions were uptaken, inducing gel deswelling. It was assumed that there was $100 \%$ uptake of the ions from solution into the hydrogel. Gel volumes and swelling changes of the hydrogels were measured using manual Vernier calipers. It was determined that the average deviation in measured gel volume was $0.4 \mathrm{~mm}^{3}$.

\subsection{Raman Spectroscopy}

Raman measurements of hydrogels were carried out on a Horiba LabRAM HR Evolution spectrometer with a $532 \mathrm{~nm}$ Laser Quantum mpc6000 laser operating at $5 \mathrm{~mW}$. The operating and analysis software used was LabSpec version 6 . The confocal hole was set to $400 \mu \mathrm{m}$ and a grating of the order 600 lines $/ \mathrm{mm}$ was used. Spectra were collected using an auto-scanning mode with twenty accumulations. Hydrated hydrogels were studied using a 10× objective, while dried hydrogels were studied under a 50× objective. Hydrated hydrogels were encased in a humidity chamber composed of a petri dish covered with Mylar film. Raman peaks associated with water, at $3000 \mathrm{~cm}^{-1}$, were used in normalization, to correct for any fluctuations in the hydration state of the gel. To produce 
dry hydrogels, gels were dried within a humidity chamber, where the humidity was incrementally decreased over the course of a few days to allow for controlled shrinkage with minimal mechanical damage. Gels were then subjected to a final drying overnight in an oven set to $60^{\circ} \mathrm{C}$.

\subsection{UV-vis Spectroscopy}

UV-vis spectroscopy of the hydrogels was carried out on a Shimadzu UV-3600 spectrometer that utilized the software UVprobe version 2.33. The hydrogels were sandwiched between quartz windows and placed in a custom-made sample holder. A gel of the same supporting electrolyte composition with no added transition metals was used as the blank reference sample. The spectra were collected from $400-1300 \mathrm{~nm}$ with a slit width of $2 \mathrm{~nm}$.

\section{Results \& Discussion}

As shown in Figure 2.1, increasing amounts of soluble iron (II) produced increasing amounts of Prussian blue within the hydrogels. Changes were observed and quantified visually (Fig. 2.1a \& b) by the increasing saturation of blue color, and also by an increase in conductivity as measured using electrochemical impedance spectroscopy (EIS) (Fig. 2.1c). The formation of the Prussian blue color over $30 \mathrm{~min}$ is depicted in Video 1, Appendix. In Video 2, Appendix, the stability of the Prussian blue complex within the hydrogels is demonstrated, as the gels maintain their depth of coloration while the excess ferricyanide leaches into fresh electrolyte. The colorimetric response of the hydrogels produced a logarithmic response (Fig. 2.1b), as has been seen in other 
colorimetric response systems [139-142]. The lower limits of detection and quantitation for the colorimetric method were $0.10 \& 0.15 \mathrm{ppm}$ in solution, respectively, with a dynamic range of $0.11-9 \mathrm{ppm}$ in solution. A UV-vis spectroscopy survey was also carried out on the PB-gels and the wavelength of the maximum absorbance remained constant at $712 \mathrm{~nm}$ and showed a similar logarithmic response to PB formation upon exposure to iron ions. The conductivity of the Prussian blue-hydrogel system (PB-gel) showed a linear response with lower limits of detection and quantitation of $0.07 \& 0.23$ ppm in solution, respectively, and a dynamic range of $0.11-11.1 \mathrm{ppm}$ in solution.

a)

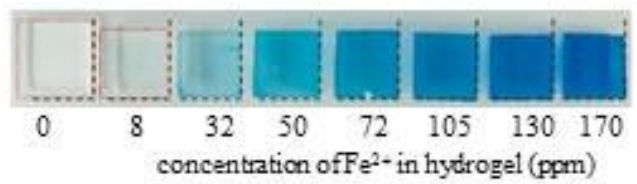

b)

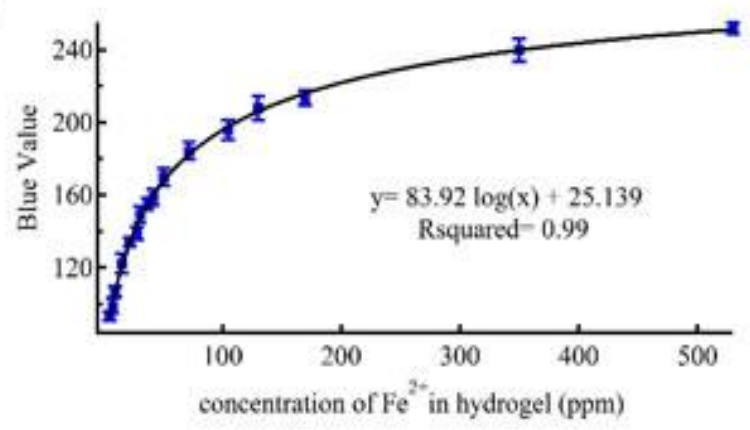

c)

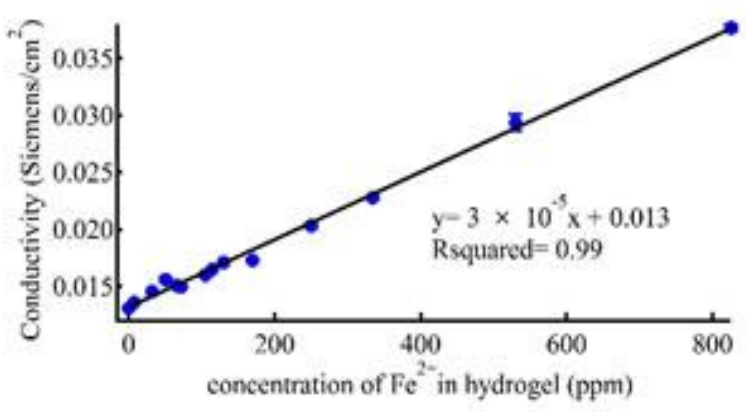

Figure 2.1: a) Photographs of the hydrogels from $0-170 \mathrm{ppm} \mathrm{Fe}^{2+}$, with reference dotted lines to aid in visualization of deswelling that occurs with increasing iron concentration. Gels at 0 \& 8 ppm are outlined in red for clarity. b) Area averaged blue value calibration curve of hydrogels at various iron concentrations. c) Conductivity calibration curve of conductivity of hydrogels at various iron concentrations. 
Because the gels accumulate ions from solution over time, the response of the hydrogels is not greatly affected by the volume of solution present, but rather primarily by the number of moles of analyte present. This property was observed experimentally when identically sized gels were exposed to solutions containing the same number of moles of iron but an order of magnitude difference between the volumes. After exposure to those solutions for two days the difference in concentration gave only a negligible $2 \%$ change in conductivity when it was measured an hour after applying ferricyanide. Had solution concentration dictated the predominant response of the gel, we would have expected a much greater increase, $\sim 40 \%$, in conductivity for the more concentrated compared to less concentrated solution. The upper limit of the dynamic range for the conductivity measurements is theoretically only curtailed by the number of ion-binding functional groups present in the hydrogel; the calculated upper limit of ion uptake in the $3 \mathrm{~cm} \times 3$ $\mathrm{cm}$ gels used here (the gels can be cut to any size) was $1425 \mathrm{ppm} \mathrm{Fe}^{2+}$ in the hydrogel. The upper limit of quantification can be increased by increasing the w/w\% of sulfonate monomer during synthesis of the hydrogels; in a test performed in our lab the w/w\% of sulfonate groups in the gels was increased by $10 \%$, which increased the upper limit to approximately $2050 \mathrm{ppm}$ in the hydrogel.

There are specific advantages to each method beyond their individual quantitative responses: the colorimetric response allows for rapid visual confirmation of the presence of iron ions, while conductivity measurements offer more robust quantitation, as it has a linear response, and may be more suitable for in-situ field measurements, where variable lighting conditions may challenge the colorimetric determination. Both techniques can be 
considered non-destructive (with the electrical method being so because the applied voltage is AC and low in amplitude). The hydrogel itself plays an important role in this sensor system, as it is anionic and thus collects and concentrates transition metal cations. In Fig. 2.1, the final concentrations of $\mathrm{Fe}^{2+}$ in the hydrogels were $100 \times$ higher than the initial concentration in the respective soaking solutions. Gel concentration increases the sensitivity of these techniques as compared to solution data: a $25 \%$ increase in sensitivity (based on the slope of the calibration curves) was seen in the gel colorimetric sensor versus solution, and a $60 \%$ increase in sensitivity for the conductivity sensor for the low to mid-range values $(0-170 \mathrm{ppm}$ in hydrogel $)$.

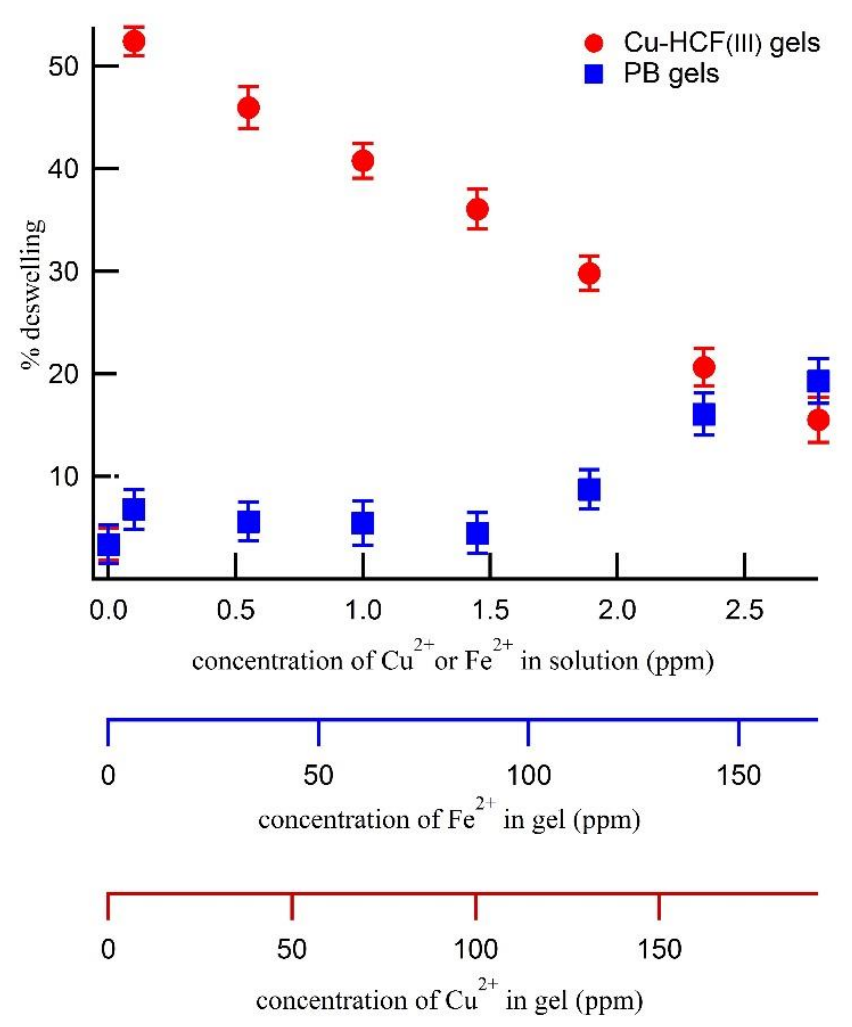

Figure 2.2: Deswelling calibration curves for varying $\mathrm{Cu}^{2+}$ or $\mathrm{Fe}^{2+}$ ion concentrations via formation of $\mathrm{Cu}-\mathrm{HCF}(\mathrm{III})$ or PB integrated hydrogels, respectively. Deswelling is defined as the ratio of the initial gel volume to the final gel volume at the given concentrations. 
Copper ions (and nine additional transition metal ions, as given in Table S1) were also detected with the same techniques, this time forming a copper hexacyanoferrate $(\mathrm{Cu}-$ $\mathrm{HCF}(\mathrm{III})$ ) complex within the hydrogel. The range of concentration detected was 0.11 - 3 ppm in the initial solution with a detection limit of $0.11 \mathrm{ppm} \mathrm{Cu}^{2+}$. In this instance, the conductance of the system decreased as the concentration of copper ions increased, the converse of iron ions.

Additional characterization of the responses of these sensors to iron and copper ions reinforced the opposing conductance trends observed. Specifically, it was observed that uptake of metal ions into the hydrogels caused the gel to either swell or shrink (deswell) by varying amounts depending on the type and amounts of transition metal ions. The swelling/deswelling phenomena, which followed a quantifiable trend (as can be seen in Figure 2.2 for $\mathrm{Cu}-\mathrm{HCF}(\mathrm{III})$ ), provide another sensing parameter. The swelling behavior for Prussian blue, while also quantifiable, showed the opposite trend: increasing deswelling (i.e. shrinkage) with increasing PB in the hydrogel. Rationale for those trends is provided by close examination of peak positions in Raman spectra.

Prussian blue formed within hydrogels can also be quantitatively detected via Infrared and Raman spectroscopy. The mid-range wavenumbers (from $900 \mathrm{~cm}^{-1}$ to 1800 $\mathrm{cm}^{-1}$ ), associated with hydrogen bonding, decrease in intensity with increasing concentration of PB within the hydrogel, as can be seen in the Raman spectra in Figure 2.3 [143-147]. As would be expected from the conductivity measurements trends, $\mathrm{Cu}-$ 
$\mathrm{HCF}(\mathrm{III})$ hydrogels display the converse Raman trend, as copper ions affect H-bonding differently than iron ions.

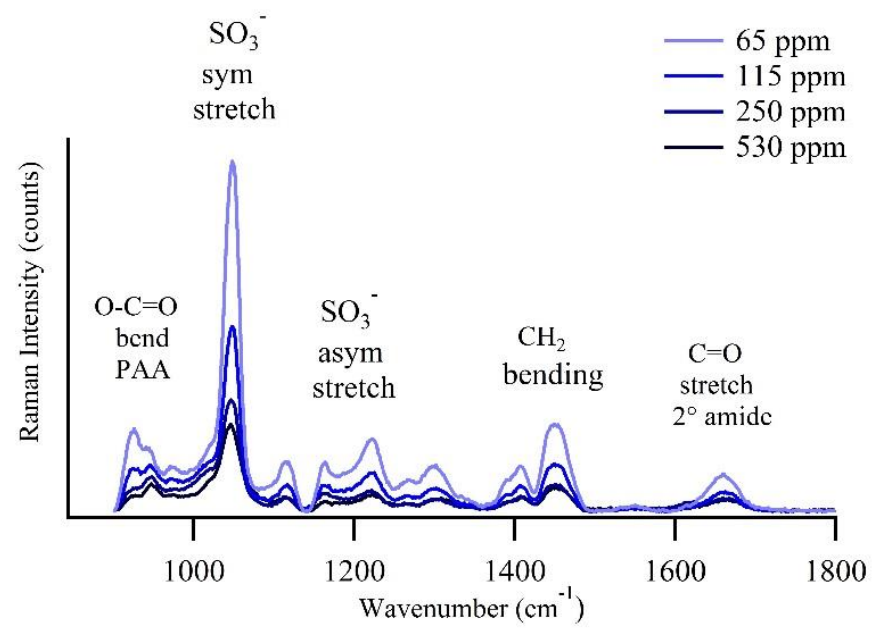

Figure 2.3: Decreasing Raman peak intensities with increasing PB concentration within the hydrogel.

Direct evidence of the metal complex interacting with the hydrogel matrix can be seen by comparison of its Raman spectrum with the $\mathrm{Cu}-\mathrm{HCF}$ (III) hydrogel and bare hydrogel (see Figure 2.4). At the lower wavenumbers (from $200 \mathrm{~cm}^{-1}$ to $700 \mathrm{~cm}^{-1}$ ), unique symmetric stretching peaks attributed to $\mathrm{Fe}-\mathrm{CN}$ and $\mathrm{Fe}-\mathrm{C}$ bonds are present only in the PB gel. As shown in the inset of Fig. 2.4, the $\mathrm{SO}_{3}{ }^{-}$symmetric stretch (from the AMPS molecule) shows slight peak position shifts, reflecting the different ion types interacting with the charged headgroup. The bare hydrogel with only electrolyte $(\mathrm{NaCl})$ present has a $\mathrm{SO}_{3}{ }^{-}$peak at $1047 \mathrm{~cm}^{-1}$, while $\mathrm{Cu}-\mathrm{HCF}$ (III)-gel shows a slight shift to 1048 $\mathrm{cm}^{-1}$ and the PB-gel has its maximum at $1051 \mathrm{~cm}^{-1}$. The shift of $4 \mathrm{~cm}^{-1}$ for PB-gel versus $1 \mathrm{~cm}^{-1}$ in the case of $\mathrm{Cu}-\mathrm{HCF}(\mathrm{III})$ gel compared to bare gel, indicates a stronger interaction between the $\mathrm{Fe}^{2+}$ and $\mathrm{SO}_{3}^{-}$than $\mathrm{Cu}^{2+}$ and $\mathrm{SO}_{3}^{-}[148]$. Characteristic strong $\mathrm{CN}^{-}$ symmetric stretches are present for both PB-gel and $\mathrm{Cu}-\mathrm{HCF}(\mathrm{III})$ gels; those Raman spectral data can be viewed in the supporting information. 


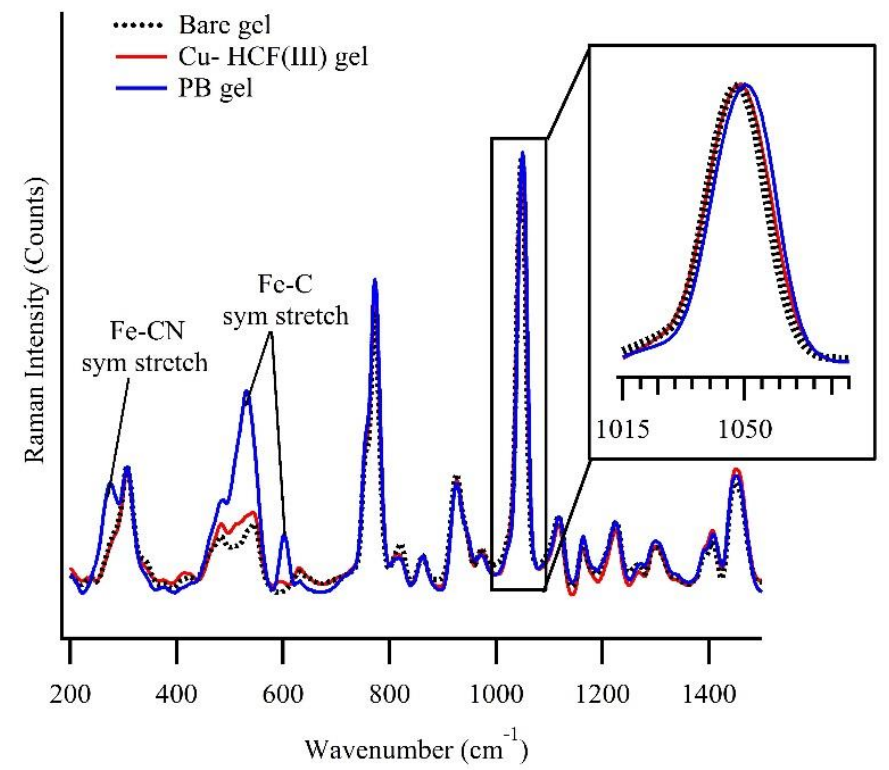

Figure 2.4: Raman spectra of gels containing Prussian blue (blue trace), Cu-HCF(III) (red trace), and a gel with no added metal ions denoted as "Bare gel" (broken lines). The inset shows a magnified view of the $\mathrm{AMPS} \mathrm{SO}_{3}{ }^{-}$symmetric stretch for all three hydrogels. Spectra are normalized to the sulfonate peak.

The law of matching water affinities drives the strength of interaction between ion and headgroup. Ferrous iron ions, when compared to cupric ions, can be expected to have a stronger interaction with the sulfonate group, based on ion size and charge density differences $[83,149]$. Thus, the opposite conductivity and swelling trends seen for PB and $\mathrm{Cu}-\mathrm{HCF}(\mathrm{III})$ gels can be explained by the differing strengths of association. Because iron ions within the $\mathrm{PB}$ complex strongly interact with $\mathrm{SO}_{3}{ }^{-}$headgroups, co-ions originally associated with those headgroups for charge balance are dislodged and experience greater mobility, reducing the electrolyte viscosity and increasing the conductivity of the hydrogel, as presented in Fig. 2.1. In contrast, because $\mathrm{Cu}^{2+}$ does not associate as strongly with the sulfonate headgroup, conductivity of the hydrogel decreases as free $\mathrm{Cu}^{2+}$ is converted into the neutral $\mathrm{Cu}-\mathrm{HCF}(\mathrm{III})$ complex. 
Deswelling trends can be similarly explained by considering the strength of transition metal ion interactions with the hydrogel headgroups, as well as the propensity of the transition metal ions to form a secondary ionic cross-linked network within the hydrogel. The strong interaction of $\mathrm{Fe}^{2+}$ (and therefore Prussian blue) with the hydrogel's headgroups causes an increase in the degree of ionic cross-linking in these highly charged, anionic hydrogels $[50,150]$. While ionic cross-linking usually causes deswelling, it also likely restricts the amount of deswelling that can occur. The stabilizing effect of ionic cross-linking can be seen when comparing the deswelling trend of $\mathrm{Cu}$ $\mathrm{HCF}(\mathrm{III})$-gels (which shows a large change in \% deswelling) to that of Prussian blue (which shows a fairly small change). For Prussian blue, it is likely the formation of a substantive three-dimensional network that, once formed, acts to prevent further loss of water, which has been reported in other studies $[88,151]$. In the case of $\mathrm{Cu}-\mathrm{HCF}(\mathrm{III})-$ gels, deswelling of the hydrogel was observed due to two factors: 1. neutralization of charge upon formation of the neutral complex and 2. the ratio of the hydrated radii of $\mathrm{Cu}$ $\mathrm{HCF}(\mathrm{III})$ and the original headgroup co-ions driving the overall increase in swelling. It is presumed that the hydrated radius of the $\mathrm{Cu}-\mathrm{HCF}$ (III) is larger than individual electrolyte ions. Therefore, when the ratio of $\mathrm{Cu}-\mathrm{HCF}(\mathrm{III})$ to electrolyte ions is greater than one, the amount of deswelling decreases. The trends for both PB and $\mathrm{Cu}-\mathrm{HCF}(\mathrm{III})$-gel deswelling can be seen in Figure 2.2.

It is noteworthy that when $\mathrm{Ni}^{2+}$ and $\mathrm{Mn}^{2+}$ hexacyanoferrate complexes are formed in the hydrogel, they follow the conductivity and deswelling trends of $\mathrm{Cu}-\mathrm{HCF}(\mathrm{III})$ and Prussian blue, respectively. This result was expected, as the hydrated radius of $\mathrm{Ni}^{2+}$ 
relates more closely to $\mathrm{Cu}^{2+}$ and that of $\mathrm{Mn}^{2+}$ to $\mathrm{Fe}^{2+}$; and their predictable behavior offer further evidence that these trends are driven by gel headgroup preference via ionic radius and charge density.

In order to provide more evidence for the hypothesis of the ion-headgroup interaction driving the swelling and conductivity trends seen in Fig. 2.1, hydrogels were equilibrated in chloride-based supporting electrolytes with varying mono- and divalent counter-cations $\left(\mathrm{Na}^{+}, \mathrm{K}^{+}, \mathrm{Cs}^{+}, \mathrm{Rb}^{+}\right.$and $\left.\mathrm{Ca}^{2+}, \mathrm{Sr}^{2+}, \mathrm{Mg}^{2+}\right)$. Hydrogels showed conductivity differences based on cation size and affinity for the gel's headgroups. The gels with various monovalent cations showed the following conductivity trend: $\mathrm{K}^{+}>\mathrm{Rb}^{+}>\mathrm{Na}^{+}>$ $\mathrm{Cs}^{+}$. When $\mathrm{Fe}^{2+}$ was then equilibrated into those various hydrogels, conductivities of the gels increased to a similar value, an average of $32 \pm 4 \mu$ Siemens. Once ferricyanide was added and Prussian blue formed, the conductivities of the hydrogels increased again to

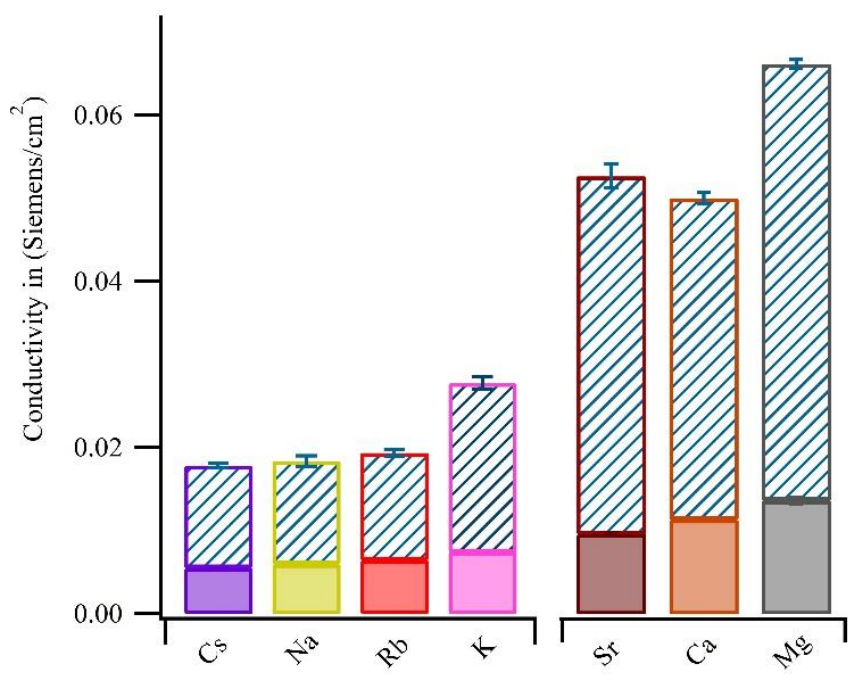

Figure 2.5: Category plot of the conductivities of hydrogels equilibrated in various chloride electrolytes. Solid bars indicate conductivities of gels with electrolyte only; the patterned bars indicate the conductivities of the gels with Prussian blue formed within the hydrogel. 
follow the same original trend: $\mathrm{K}^{+}>\mathrm{Rb}^{+}>\mathrm{Na}^{+}>\mathrm{Cs}^{+}$, as can be seen in Figure 2.5. $\mathrm{K}^{+}$as a supporting electrolyte showed a particularly large increase in conductivity after the formation of Prussian blue. It is known that Prussian blue formed in the presence of $\mathrm{K}^{+}$ ions is considered to be a water soluble form of Prussian blue, where $\mathrm{K}^{+}$ions occupy interstitial spaces in the lattice framework $[152,153]$. These $\mathrm{K}^{+}$ions act as a charge balance, and as such the stoichiometry of the complex changes from $\mathrm{Fe}(\mathrm{III})_{4}\left[\mathrm{Fe}(\mathrm{II})(\mathrm{CN})_{6}\right]_{3}$ to $\mathrm{K}_{4} \mathrm{Fe}(\mathrm{III})_{4}\left[\mathrm{Fe}(\mathrm{II})(\mathrm{CN})_{6}\right]_{3}$. This change in structure likely contributes to the extra increase in conductivity seen in Figure 2.5. Divalent cations were observed to have an increase of roughly double the conductivity versus the monovalent ions, as would be expected. $\mathrm{Mg}^{2+}$, according to the law of matching water affinities, should have the least affinity for the AMPS groups and indeed it has the highest conductivity, while $\mathrm{Ca}^{2+}$ and $\mathrm{Sr}^{2+}$ have lower conductivities. Finally, it is notable that when the calculated gel uptake capacity is surpassed with a high concentration of $\mathrm{Fe}^{2+}$, the trends described above were not observed; in that case it was the excess iron ions that dominated conductivity of the hydrogel. For the same reasons, if the electrolyte salt concentration was increased above the uptake capacity, the trends were again not visible.

In the course of this study, many different metal hexacyanoferrate complexes were formed within the hydrogels. A small sampling of the complexes that display obvious unique colorimetric and swelling changes are shown in Figure 2.6. A list of the colors seen for metal hexacyanoferrate complexes formed during the course of this study can be found in S1. These results suggest that combined spectral information and conductivity measurements will allow for identification and quantitation of a range of 
different transition metal ions.

4. Conclusion

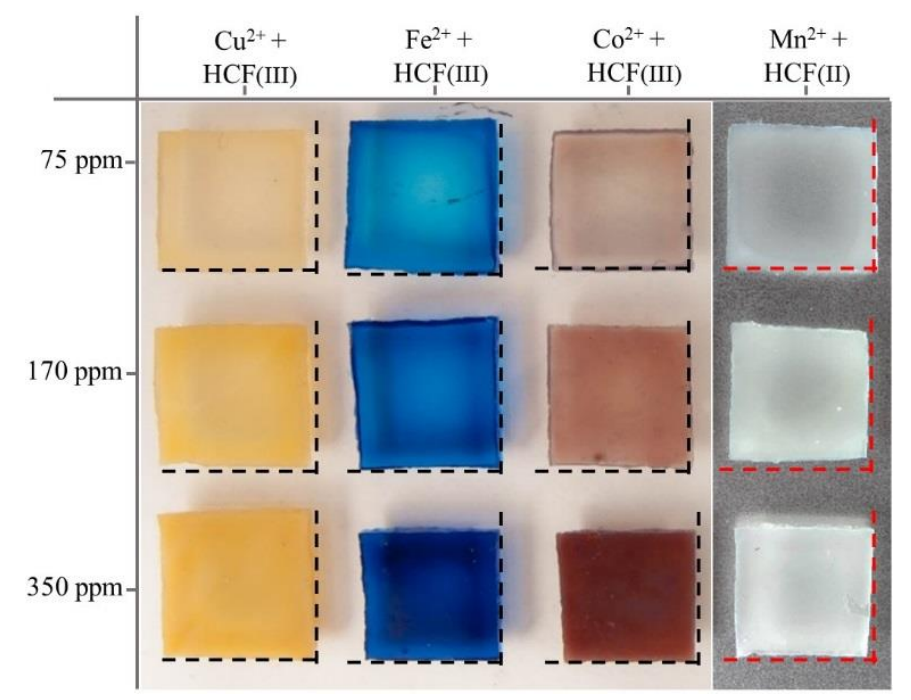

Figure 2.6: $3 \times 3 \mathrm{~cm}$ hydrogels exposed to various transition metal ions that produce different colored complexes upon addition of hexacyanoferrate. Swelling changes can be seen with varying (in gel) concentration. Gels with manganese ions are are shown on a gray background to increase contrast. The dashed lines correspond to $3 \times 3 \mathrm{~cm}$, and are shown to enable comparison of relative deswelling of the gels.

Hydrogels were used as a sensor for transition metal ions, utilizing the responsive behavior of the hydrogels for a variety of detection methods - photonic, chemoresistive, and vibrational - which can be employed in unison as confirmatory methods, or in tandem based on available instrumentation. An understanding of the physical chemical principles governing aqueous electrolytes provides the necessary insight to interpret data trends. Because the high charge-density of the gel's headgroups preconcentrate transition metal ion analytes, detection limits approach the ppb level. Altering the hydrogel headgroup type, density and supporting electrolyte type and concentration would enable these sensors to be further optimized for sensitivity to different types and concentrations of transition metal ions. It is conceivable that a matrix of hydrogels of differing 
compositions could be deployed as a sensor array for various ion concentrations and

types.

\section{Supplementary Material}

Table 2.1: List of transition metal ion solutions and the respective colors formed when combined with either HCF(III) (ferricyanide) or HCF(II) (ferrocyanide).

\begin{tabular}{|c|c|c|c|}
\hline Transition Metal Ion & Hexacyanoferrate Ion & Color Formed & $\begin{array}{c}\text { Clear or } \\
\text { Precipitate }\end{array}$ \\
\hline $\mathrm{Cu}^{2+}$ & HCF(II) & Dark Red & Clear \\
\hline$* \mathrm{Cu}^{2+}$ & HCF(III) & Golden yellow & Precipitate \\
\hline $\mathrm{Pb}^{2+}$ & $\mathrm{HCF}(\mathrm{II})$ & White & Precipitate \\
\hline $\mathrm{Pb}^{2+}$ & HCF(III) & No color change observed & $\mathrm{n} / \mathrm{a}$ \\
\hline $\mathrm{Al}^{3+}$ & $\mathrm{HCF}(\mathrm{II})$ & No color change observed & $\mathrm{n} / \mathrm{a}$ \\
\hline $\mathrm{Al}^{3+}$ & HCF(III) & No color change observed & $\mathrm{n} / \mathrm{a}$ \\
\hline $\mathrm{Co}^{2+}$ & $\begin{array}{c}\mathrm{HCF}(\mathrm{II}) \text { (note: presence } \\
\text { of } \mathrm{Na}^{+} \text {required) }\end{array}$ & Grayish aqua & Precipitate \\
\hline$* \mathrm{Co}^{2+}$ & HCF(III) & Reddish brown/purple & Clear \\
\hline $\mathrm{Sn}^{2+}$ & HCF(II) & White & Precipitate \\
\hline $\mathrm{Sn}^{2+}$ & HCF(III) & No color change observed & $\mathrm{n} / \mathrm{a}$ \\
\hline $\mathrm{Cd}^{2+}$ & HCF(II) & Cloudy white & Likely Precipitate \\
\hline $\mathrm{Cd}^{2+}$ & HCF(III) & Bright yellow & Precipitate \\
\hline $\mathrm{Cr}^{2+}$ & $\mathrm{HCF}(\mathrm{II})$ & No color change observed & $\mathrm{n} / \mathrm{a}$ \\
\hline $\mathrm{Cr}^{2+}$ & HCF(III) & No color change observed & $\mathrm{n} / \mathrm{a}$ \\
\hline$* \mathrm{Mn}^{2+}$ & HCF(II) & Cloudy white & Likely precipitate \\
\hline $\mathrm{Mn}^{2+}$ & HCF(III) & No color change observed & $\mathrm{n} / \mathrm{a}$ \\
\hline $\mathrm{Mn}^{2+}$ & Mixed (II/III) & Brown & Precipitate \\
\hline $\mathrm{Zn}^{2+}$ & $\mathrm{HCF}(\mathrm{II})$ & Yellow/brown & Precipitate \\
\hline $\mathrm{Zn}^{2+}$ & HCF(III) & Yellow/brown & Precipitate \\
\hline $\mathrm{Ni}^{2+}$ & HCF(II) & Yellow/brown & Precipitate \\
\hline $\mathrm{Ni}^{2+}$ & HCF(III) & Yellow/brown & Precipitate \\
\hline $\mathrm{Zr}^{2+}$ & HCF(II) & No color change observed & $\mathrm{n} / \mathrm{a}$ \\
\hline $\mathrm{Zr}^{2+}$ & HCF(III) & No color change observed & $\mathrm{n} / \mathrm{a}$ \\
\hline $\mathrm{Mo}^{5+}$ & $\mathrm{HCF}(\mathrm{II})$ & Orange & Clear \\
\hline $\mathrm{Mo}^{5+}$ & HCF(III) & No color change observed & $\mathrm{n} / \mathrm{a}$ \\
\hline $\mathrm{Ag}^{+}$ & $\mathrm{HCF}(\mathrm{II})$ & No color change observed & $\mathrm{n} / \mathrm{a}$ \\
\hline $\mathrm{Ag}^{+}$ & HCF(III) & Orange & Precipitate \\
\hline
\end{tabular}

* denotes an ion combination shown in the photograph of Figure 2.6 
The Raman spectra of gels containing Prussian blue (PB) or copper ferricyanide (Cu- $\mathrm{HCF}(\mathrm{III})$ ) can be compared to that of a hydrogel containing only $\mathrm{NaCl}$ (Bare) to find a number of characteristic peaks. At 2114 and $2150 \mathrm{~cm}^{-1}$ are the strong symmetric stretches of cyanide groups, present only in the gel spectra of metal hexacyanoferrate complexes (M-HCF). Both are shifted away from the typical free cyanide stretch of 2080 $\mathrm{cm}^{-1}$, indicating a change in energy due to bonding to metal ions [153]. The mid wavenumber range of approximately $700-1800 \mathrm{~cm}^{-1}$ contains peaks primarily originating from the hydrogel structure $[148,154-156]$. In the low wavenumber range of approximately $50-650 \mathrm{~cm}^{-1}$ there are a few relatively weaker intensity peaks in the bare gel, while in the hydrogels containing M-HCF hydrogels the same peaks are present, with the addition of characteristic M-HCF peaks as follows. The peaks at 506 and $595 \mathrm{~cm}^{-1}$ were assigned to $\mathrm{Fe}-\mathrm{C}$ stretches [153, 157-159], the slightly lower wavenumber peak of $475 \mathrm{~cm}^{-1}$ to a Fe-N stretch $[157,159,160]$, the peak at $357 \mathrm{~cm}^{-1}$ to bending of Fe-CN [153, 159-161], and $208 \mathrm{~cm}^{-1}$ to bending of N-Fe-N [160]. It is possible that the heightened intensity of the peak at $96 \mathrm{~cm}^{-1}$ is due to a bending peak of C-Fe-C in the gels contained M-HCF, but that is not clear [153].

Copper ions form a dark red complex when reacted with ferrocyanide and a golden yellow complex when reacted with ferricyanide, as denoted in Table S1. In Figure S2.7, the Raman spectra of the two species are compared to gel only. Spectral intensity and wavenumber differences between the two complexes can be seen primarily in the high energy region, although there is also a significant difference between the $\mathrm{CN}^{-}$ peaks in the $2000-2200 \mathrm{~cm}^{-1}$ region. 


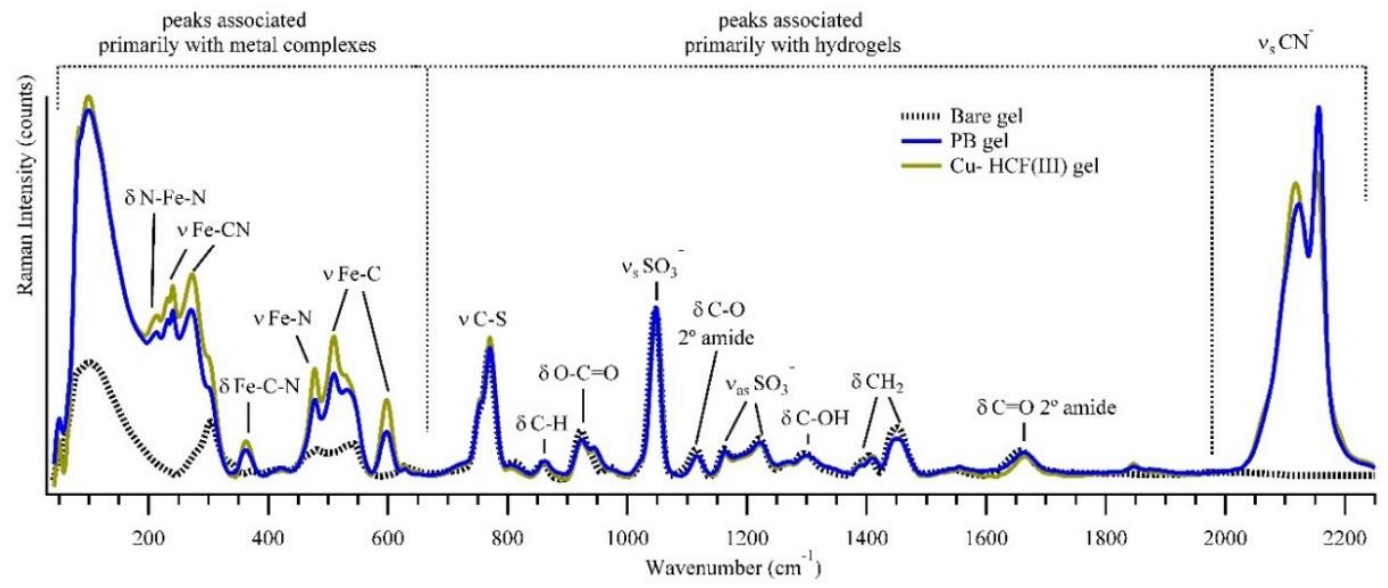

Figure 2.8: Raman spectra of gels containing Prussian blue and copper ferricyanide (Cu-HCF(III)) and a gel without added complex, denoted as "Bare gel". Spectra are intensity normalized to the sulfonate peak at $1040 \mathrm{~cm}^{-1}$.

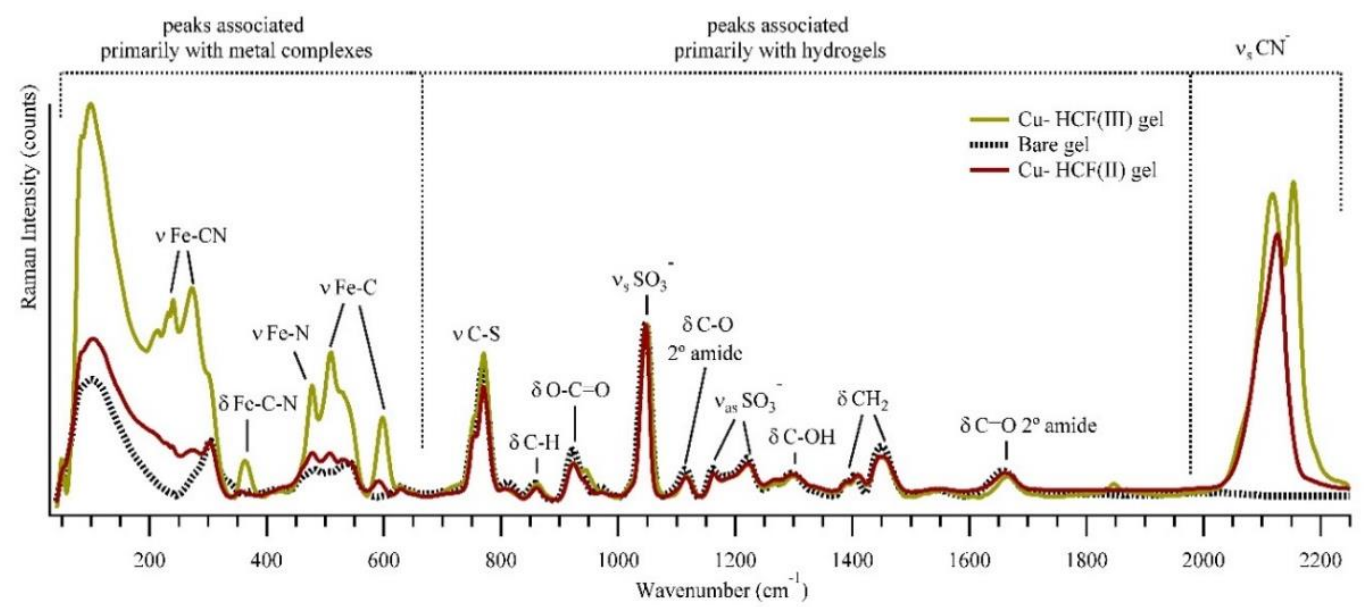

Figure 2.7: Raman spectra of gels containing copper ferricyanide $(\mathrm{Cu}-\mathrm{HCF}(\mathrm{III}))$ and copper ferrocyanide (Cu-HCF(II)) and a gel without added complex, denoted as "Bare gel". Spectra are intensity normalized to the sulfonate peak at $1040 \mathrm{~cm}^{-1}$. 
Chapter 3: Rapid quantitative photonic and impedimetric responses of hydrogel-based sensors for the in situ evaluation of corrosion inhibitors on steel

\section{ABSTRACT}

A direct sensor to quantitatively evaluate the inhibitory performance of a range of fatty acid corrosion inhibitors for steel is described. The sensor consists of a buffered polymeric hydrogel of 2-acrylamido-2-methylpropanesulfonic acid and poly(acrylic acid), equilibrated in potassium ferricyanide. This sensor responds to soluble transition metal ions by complexation to produce metal hexacyanoferrate, a process which rapidly induces measureable spectroelectrochemical changes. The aliphatic chain lengths of the organic acids evaluated ranged from one (formic acid) to twenty-two (behenic acid). Based on the understanding that comparatively ineffective corrosion inhibitors evolve soluble transition metal ions from the substrate in greater concentration than more effective inhibitors, production of the metal complex is quantified in two ways: colorimetrically and impedimetrically. X-ray photoelectron spectroscopy (XPS) was utilized to characterize differences in the surface chemistry across the range of inhibitors studied and to connect this work to other studies that investigated the surface coverage of some of the same molecules on steel. The contextualization of our simple, quantitative sensor responses via XPS and published literature suggest an improvement over current corrosion testing techniques, offering earlier, in situ detection with an understanding of the surface processes usually limited to advanced, high-vaccum techniques such as XPS. 


\section{INTRODUCTION}

In 2016, the National Association of Corrosion Engineers (NACE) estimated the worldwide cost of corrosion to be $\$ 2.5$ trillion U.S. dollars, or $3.4 \%$ of the global GDP [2]. To reduce corrosion costs, NACE encouraged the implementation of corrosion management systems along with advanced anti-corrosion technology [2]. One remaining challenge is developing the capability to sense preliminary stages of corrosion, which would inform and direct treatment decisions while reducing corrosion costs by an estimated 30\% [40, 162]. Electrochemical and advanced spectroscopic techniques are methods currently used for corrosion sensing $[\underline{6-8}, \underline{13}, \underline{23}, \underline{29}, \underline{163-166]}$. However, those techniques are not widely used in-situ, because they are difficult to adapt for field use, such techniques are often expensive, require a great deal of interpretation and training to use, and only detect the later stages of corrosion. There exists a need for inexpensive, robust, non-destructive, sensitive and easily interpreted corrosion-detection methodologies that can quantify the initial markers of corrosion.

Hydrogels offer the possibility of capturing and detecting markers of early corrosion (i.e. soluble transition metal ions) through a variety of chemical and physical responses [28, 33-35]. Hydrogels can bind transition metal ions that, when reacted with hexacyanoferrate ions, $[\mathrm{FeII}(\mathrm{CN}) 6] 4-$ or $[\mathrm{FeIII}(\mathrm{CN}) 6] 3^{-}$, form complexes in the gel having the general structure $\mathrm{Mx}+[\mathrm{Fe}(\mathrm{CN}) 6] \mathrm{y}-\mathrm{x} / \mathrm{y}$, where $\mathrm{M}=$ transition metal, which cause the electrical, spectral and mechanical properties of the material to be altered in measurable ways [72]. Iron hexacyanoferrate complexes, or Prussian blue (PB), are the most well-known complexes to form [96, 167], but many transition metals form similar 
complexes (e.g. $\mathrm{Cu} 2+$ [116], Ti4+ [117], Cr3+ [118], Sn4+, Al3+, Mn2+, Zn2+ [93], $\mathrm{Co} 2+, \mathrm{Ni} 2+, \mathrm{Pd} 2+, \mathrm{In} 3+[92], \mathrm{Ga} 2+[119], \mathrm{Y} 3+[\underline{120}], \mathrm{Zr} 4+[121], \mathrm{Ag}+[122], \mathrm{Cd} 2+$ [123], La3 $+[124], \mathrm{Pb} 2+[\underline{125}], \mathrm{Pt} 2+[\underline{126}]$, and $\mathrm{Bi} 3+[\underline{127]})$, offering the potential for as many different ion-specific sensors. Hydrogel composition can be varied by changing the headgroup identity [ $\underline{67-71]}$ or by altering the monomer and/or cross-linker ratios [168170], resulting in tailored chemical and mechanical properties towards a specific analyte or sensor setup $[\underline{75}, \underline{107}, \underline{171]}$. The flexibility and conformability of hydrogels, as well as their self-containing, encapsulatory nature, greatly increases their utility compared to inflexible and solution-based sensors and actuators [138, 172-174].

While in the past, heavy metals (e.g. chromates and molybdates) or other inorganic oxides (e.g. phosphates and nitrates) were used as corrosion inhibitors, more environmentally-benign alternatives are finding greater usage, such as saturated fatty acids; carboxylic acids with methyl-terminated hydrocarbon chains of varying length [175-178]. Specific studies evaluating the efficacy of methyl-terminated fatty acids on steel as corrosion inhibitors are virtually non-existent; yet, related studies on the structures of such monolayers on steel offer an understanding of the fundamental trends to infer their inhibitory efficacy. As the chain length of fatty acids increase, the aliphatic tails experience greater intermolecular forces, which allows for a greater degree of order, crystallinity, and self-assembly than shorter chain lengths [179-182]. These increased intermolecular forces reduce the intermolecular distance at the interface, producing

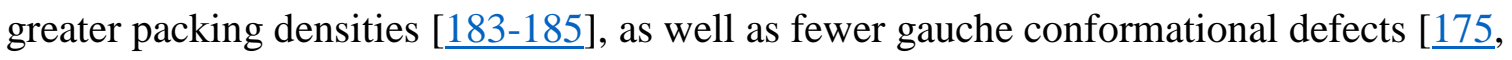
$\underline{186}, \underline{187]}$, yielding a greater protective quality against corrosion [188-190]. 
Here, the effectiveness of saturated fatty acid corrosion inhibitors having a range of aliphatic chain lengths (i.e. formic, butyric, hexanoic, decanoic, myristic, stearic, arachidic and behenic) were studied to compare and contrast our sensing methodologies to established methods. Comparing the colorimetric response of hydrogels to their impedimetric response gives greater insight to the behavior of transition metal ions within. X-ray photoelectron spectroscopy allows mechanistic interpretation related to other fundamental studies and the evaluation of the relative effectiveness of the fatty acid corrosion inhibitors studied. This work demonstrates a simple methodology using hydrogels to quantitatively evaluate the efficacy of different corrosion inhibitors and detect the earliest stages of corrosion.

\section{METHODS}

\subsection{Synthesis of Hydrogels}

Hydrogels were synthesized via a previously published method [138], using the sodium salts of 2-acrylamido-2-methylpropanesulfonic acid (AMPS; $50 \mathrm{wt} \%$ solution) and poly(acrylic acid) (PAA; average MW 5100, $50 \mathrm{wt} \%$ solution) as the co-monomers, with N,N'-methylenebis(acrylamide) (MBA; $1 \mathrm{wt} \%$ solution) as the cross-linker. Polymerization occurred via free radical reactions with potassium persulfate and metabisulfite as the initiators. Glycerol was used as a humectant. All chemicals were purchased from Sigma-Aldrich and used without further purification.

The hydrogels typically polymerized within an hour. They were then removed from their molds and allowed to equilibrate with the chosen supporting electrolyte or buffer for at least two hrs, a process that also removes unreacted monomers and allows 
for greater homogeneity in the gel. The electrolyte or buffer was then replaced with a new aliquot of solution and the hydrogels were again equilibrated for two hrs. The thickness of the hydrogel after this process was typically $3.0 \pm 0.2 \mathrm{~mm}$.

The primary buffer used in this work was a $0.1 \mathrm{M}$ tris buffer, Tris(hydroxymethyl)aminomethane, VWR Ultra-Pure Grade) at a $\mathrm{pH}$ of 7. The $\mathrm{pH}$ was measured using an Oakton Ion 510 Series meter and was adjusted using $1 \mathrm{M}$ hydrochloric acid as necessary.

\subsection{Preparation of Steel Plates}

SAE 1008/1010 3" × 6" steel panels were purchased from Q-Labs (chemical composition 0.60\% max Manganese, 0.15\% max Carbon, 0.030\% max Phosphorus, $0.035 \%$ max Sulfur). Preparation of the panels began by soaking them in xylenes for approximately an hour to remove any non-polar contaminants from the surface. They were then removed from the xylene bath, wiped with a clean lint-free cloth and placed into a bath of isopropanol for approximately $20 \mathrm{~min}$ to solubilize the xylenes. The plates were then sanded with 320, 400, 600, $800 \& 1000$ grit wet/dry sandpaper (McMasterCarr), alternating directions, until a smooth, reflective surface was obtained. Afterwards the plates were immediately sonicated (Bransonic PC-620) in isopropanol to remove any leftover sanding grit. The sonication process continued until a white, clean lint-free cloth soaked in isopropanol showed no signs of discoloration when wiped across the plate. The plates were then dried with nitrogen and treated with corrosion inhibitors as soon as possible (no more than two hours elapsed between preparation and treatment). 


\subsection{Treatment of Steel Plates with Corrosion Inhibitors}

Seven fatty acids were tested for use as corrosion inhibitors in this study: butyric, hexanoic, decanoic, myristic, stearic, arachidic and behenic acid, all obtained from TCI America at $98 \%$ purity or higher. Butyric, hexanoic, decanoic, myristic and stearic acid were dissolved in $95 \%$ ethanol to make a $10 \mathrm{mM}$ solution. Arachidic and behenic were dissolved at the same concentration in a 4:1 mix of 95\% ethanol and chloroform. Stearic acid was also dissolved in this same 4:1 mix and re-analyzed to compare the results to the prior stearic acid in ethanol alone.

Freshly prepped steel plates were placed in glass Pyrex dishes and covered with freshly prepared fatty acid solution. Nitrogen was bubbled through the solution for approximately $20 \mathrm{~min}$, then the solution was covered and left for $24 \mathrm{hrs}$. At the 24 hour mark the plates were removed and sonicated in ethanol for five min to remove any solely physisorbed molecules. The plates were then removed, dried with nitrogen and any desired analysis performed immediately. Three other treatments were used as a control: freshly sanded plates with no other treatment, plates soaked in $95 \%$ ethanol, and plates soaked in $10 \mathrm{mM}$ formic acid.

The plates analyzed with X-ray photoelectron spectroscopy (XPS) were prepared in similar fashion, but with semiconductor grade solvents and while minimizing the exposure of the plates to air to avoid the buildup of superfluous adventitious carbon.

\subsection{Colorimetric Analysis of Corrosion Inhibitors}

The equilibrated hydrogels were cut into $3 \mathrm{~cm} \times 4 \mathrm{~cm}$ pieces, then a small aliquot 
of $15 \mathrm{mM}$ potassium ferricyanide (Acros Organics 99+\%) was pipetted evenly across the surface and allowed to equilibrate for 30 minutes. Once the 30 min were completed, three hydrogels were placed on each steel plate and the plate was then placed in a photography light box (ESDDI 32" × 32" with 85W E27 daylight fluorescent light bulbs). A Nikon camera was custom white-balanced to the light conditions with a Munsell X-rite Card and images were taken with f/10 with 1/15 second exposure and an ISO of 200. Images were taken at $0,15,30,45,60 \& 75 \mathrm{~min}$.

The images taken at $60 \mathrm{~min}$ were chosen for analysis, as there was not a significant increase in the amount of Prussian blue seen after this time point. "Blank" gels, with the ferricyanide, but with a sheet of Mylar forming a barrier between the hydrogel and the steel plate, were also photographed. All the images were color-balanced to the Munsell X-rite Card and straightened in Adobe Lightroom, version 2015.7. They were then imported into ImageJ 1.50i and the RGB threshold color set to the average + $6 \times$ standard deviation of the control gels. The histogram values were obtained through ImageJ's particle analysis macro. The histogram values were converted to $\mathrm{Fe}^{2+}$ quantities through a previously obtained calibration plot [72], which was adjusted for differences in background values.

\subsection{Electrochemical Impedance Spectroscopy}

Measurements were made using a Gamry 600 reference potentiostat with Echem Analyst software. Spectra were run from $1 \mathrm{MHz}-0.1 \mathrm{~Hz}$ with $20 \mathrm{mV}$ applied AC potential versus the open circuit potential. Hydrogels soaked in tris buffer (described above) and cut to $3 \mathrm{~cm} \times 3 \mathrm{~cm}$ were used as a solid electrolyte, a methodology described 
elsewhere [138]. Silver foil pieces were used as the counter and working electrodes, with PDMS spacers to control the hydrogel area. Hydrogel dimensions were measured using manual calipers and the exact surface area used for normalization. The spectra were fit to equivalent electrical circuits (EECs) for interpretation.

\subsection{X-ray photoelectron spectroscopy}

X-ray photoelectron spectroscopy was performed using a Phi VersaProbe II instrument with a $200 \mu \mathrm{m}$ beam, coupled with Multipak software. High-resolution spectra were collected at a pass energy of $23.5 \mathrm{eV}$ with $0.025 \mathrm{eV}$ step resolution and a time of 0.8 seconds per step, while survey quality spectra were collected with a pass energy of 187.85 $\mathrm{eV}$ with $1.6 \mathrm{eV}$ step resolution.

Peak fitting was performed with phi MultiPak software, version 9.5.0.8. An iterated-Shirley background with Gaussian-Lorentzian peak fits were used. Trends in the relative peak areas were interpreted utilizing established understanding of attenuation of photoelectrons with increasing carbon chain length [191, 192].

\section{RESULTS \& DISCUSSION}

Formation of PB within hydrogel sensors demonstrated the evolution of soluble iron species from steel substrates, thus indicating active corrosion. Substrates treated with different chain lengths of fatty acids showed discernible trends in the average amount of PB formed within the hydrogel sensors, as shown in Fig. 3.1a. The images in Fig. 3.1b show the sensors in situ: hydrogels containing ferricyanide were placed on steel substrates treated with a range of corrosion inhibitors. The spots of PB that formed varied in their blue tone and size. To capture the distribution of the responses on each sensor, 
blue values of each spot were measured, compared to calibrated PB hydrogels [72], and the results were plotted in Fig. 3.1a. The histograms in Fig. 3.1a show that the range and average amount of $\mathrm{Fe}^{2+}$ present. It was generally observed that for the plates treated with

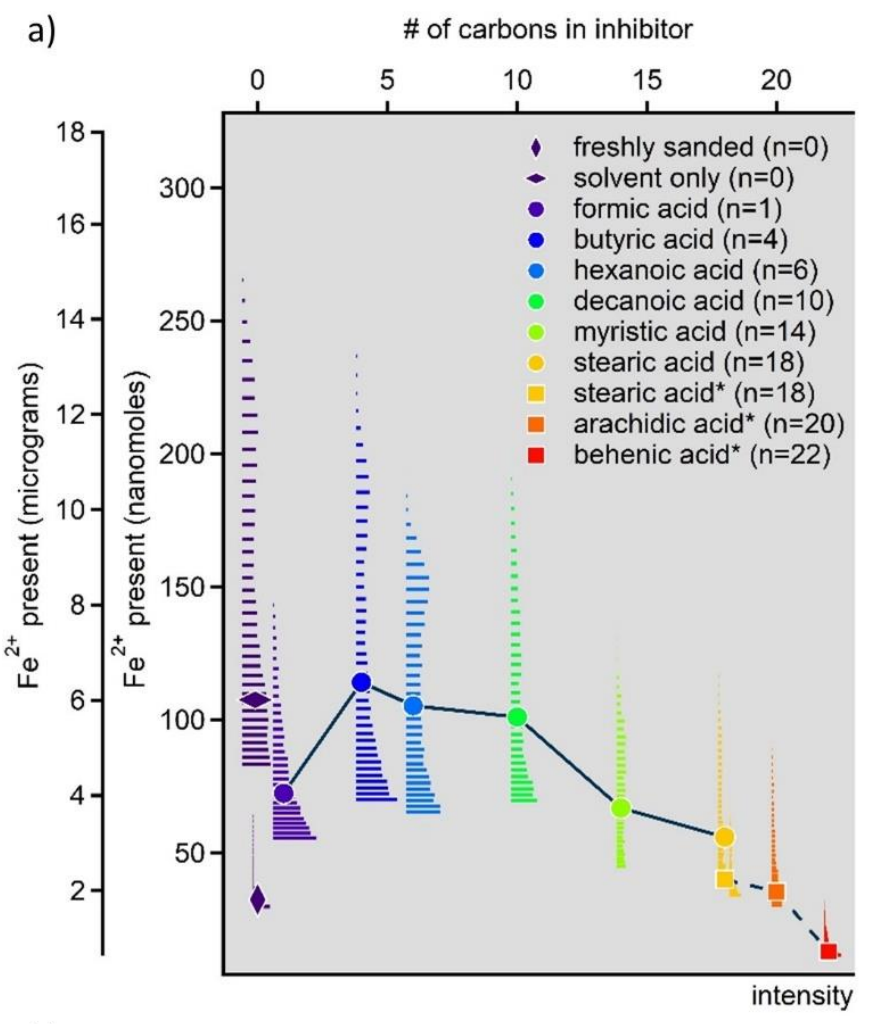

b)

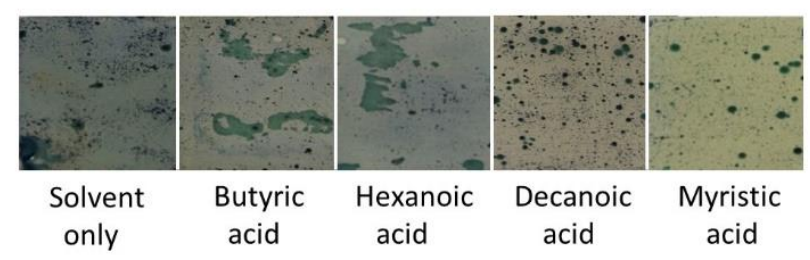

Figure 3.1: a) Heat map of nanomoles of $\mathrm{Fe}^{2+}$ detected based on the calibrated colorimetric response for each of the inhibitors evaluated, where $n=$ the number of carbons in the inhibitor. Two controls were utilized; "solvent only" refers to a plate soaked in ethanol without inhibitor, while "freshly sanded" refers to a plate tested immediately after sanding. The solid blue line represents the average nanomoles of $\mathrm{Fe}^{2+}$ detected on substrates that had been prepared using corrosion inhibitor dissolved in ethanol alone, while the dashed line and squares indicate the same except the inhibitors were dissolved in a 4:1 mixture of ethanol and chloroform (required for solubility reasons), also indicated by asterisks in the legend. The horizontal diamond marker indicates the average for 'solvent' and the horizontal diamond marker indicates the average for 'freshly sanded'. b): Images showing the range of $P B$ formation behavior. The increasing yellow coloration evident in the images moving to the right is due to unreacted ferricyanide remaining within the gel. 
the longer chain fatty acids (>10 carbons), the gels had formed smaller, more localized spots of $\mathrm{PB}$, in shapes with greater circularity, while the shorter fatty-acid chains (approximately 0-6 carbons) formed PB in larger, irregular areas across larger regions of the sensor, as can be seen in Fig 3.1b. Considering the pKa values of the different acidic headgroups aids in interpretation of the singular exception to the overall trend, which was seen in formic acid-treated plates. Formic acid, having a pKa of 3.75 is lower than the other acids (which range between 4.5-5); and given its greater acidity, it that likely led to increased corrosion, producing insoluble iron species. That hypothesis was supported by visual inspection, which revealed orange corrosion products on the formic acid-treated plate (which were not present on any of the other inhibitor-treated plates).

The overall trend of improved corrosion inhibition with increasing fatty acid chain lengths is ascribed to multiple factors, including higher melting points with longer chain lengths, and therefore increased intermolecular forces. Inhibitors having chain lengths $<10$ have melting points below room temperature; and it is interesting to note that corrosion inhibitor performance increases most substantially as the melting points increase above room temperature (e.g. myristic, with 14 carbons has a melting temperature of $54.2^{\circ} \mathrm{C}$ ). The two longest chains tested, arachidic and behenic acid, are too nonpolar to be dissolved in ethanol alone, and therefore were dissolved in a 4:1 ethanol/chloroform mixture. To enable comparison with the shorter chain data set $(\mathrm{n}=1$ 18), where only ethanol was the solvent, stearic acid was also dissolved in the $4: 1$ ethanol to chloroform ratio. When stearic acid was dissolved in the 4:1 mixture, the amount of PB formed on the plate decreased slightly, likely due to improved solubility that allowed for better dispersion compared to the ethanol-only solutions. That this simple colorimetric 
technique detected differences in the inhibitory nature of these monolayers demonstrates the excellent sensitivity of the sensors.

As can be seen in Figure 3.2, there were also instances where deliberate damage (scratches) on the plate were distinguishable by the localized formation of PB along the contours of the damage. The ability to detect such localized damage would allow for area-specific treatment, therefore lessening repair costs.

a)

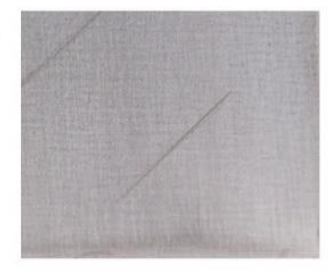

b)

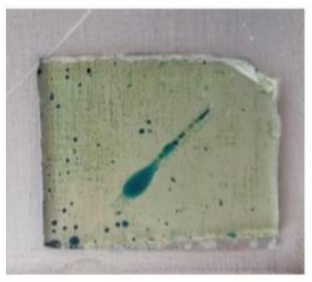

Figure 3.2: a) Steel plate with line scratched through a stearic acid film and into the metal. b) Image taken 30 min after gel was applied.

The hydrogel sensors were also evaluated for their electrochemical response to transition metal ions and to the formation of PB. Standard cell EIS (using a standard glass cell with liquid electrolyte) was attempted but proved unsuccessful, as the plates corroded too quickly under the strong electrolyte. Hydrogel cell EIS provided a successful alternative, as it lessens the oxidative conditions compared to standard cell EIS and has been found to be more sensitive to surface phenomena [193]. Typical Bode plots for plates treated with and without corrosion inhibitor are shown in Figure 3.3. At the highest frequencies, instrumental inductance was present. The solution resistance of the hydrogel was seen in the high- to mid-range frequencies, before a capacitive region attributed to 


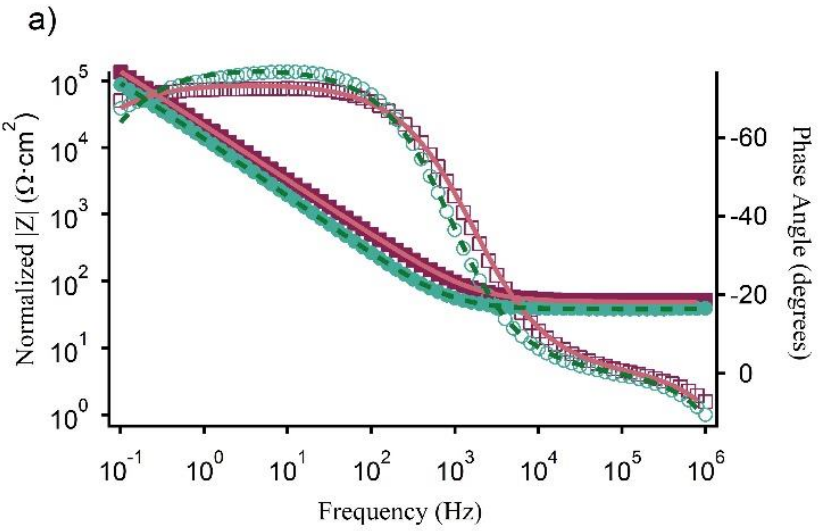

b)

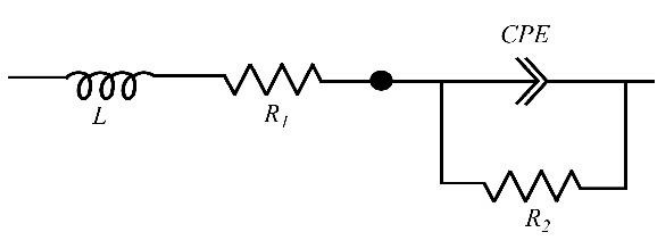

Figure 3.3: a) Representative impedance plots of corrosion inhibitors on steel. Green circles represent a plate tested immediately after sanding with no inhibitors added. Pink squares represent a plate modified with stearic acid. Closed markers are the impedance modulus spectra, while open markers are the phase angles. b) Equivalent circuit model used to fit all the EIS plots without added ferricyanide. $L=$ inductor, $R_{I}=$ solution resistance, $C P E=$ constant phase element and $R_{2}=$ charge transfer resistance.

the double layer formed at the interface of the steel and the hydrogel solid electrolyte. At the lowest frequencies, the beginnings of a resistor was seen, and attributed to the charge transfer resistance. Greater insight into the inhibitory behavior of the treated panels can be gained from closely examining the individual circuit element(s) that vary depending on surface treatment. As can be seen in Figure 3.4, the CPE-P values closely follow the quantitative colorimetric trend. The freshly sanded plate had a CPE-P value of 0.8644 , while the plates soaked for $24 \mathrm{hrs}$ showed an increase in the CPE-P value, signifying the formation of more charged species at the surface. However, with increasing length of aliphatic chain, the CPE-P value once again decreased, as the aliphatic chain blocked access of the electrolyte to the plate surface, as is consistent with other studies [194]. In 


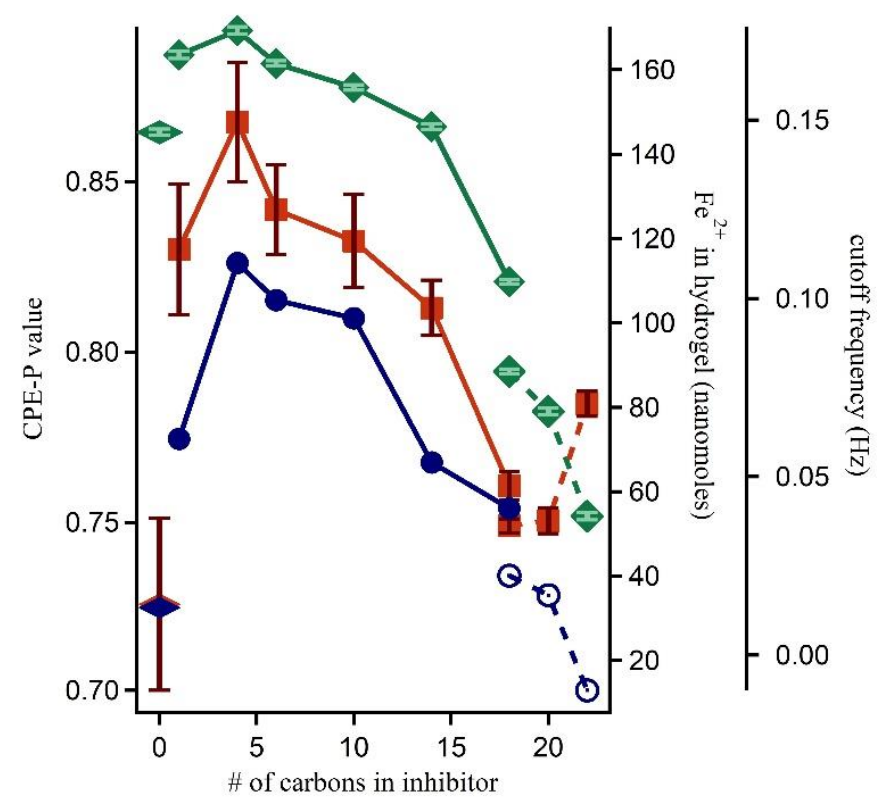

Figure 3.4: Comparison of colorimetric trends with EIS CPE-P values and cutoff frequencies. Blue circle markers represent the average nanomoles of $\mathrm{Fe}^{2+}$ present, the green diamond markers are the plotted CPE-P values and the red square markers are the cutoff frequencies. The solid lines represent corrosion inhibitors that were dissolved in ethanol alone, while the dashed lines represent corrosion inhibitors that were dissolved in a 4:1 mixture of ethanol and chloroform. The disconnected diamond markers represent freshly sanded plates.

the case of formic acid, since it lacks a chain of any length, its CPE-P value suggests the formation of an oxide layer that partially prevented the formation of charge layers at the surface. The cutoff frequency, calculated as $v_{\text {cutoff }}=1 /\left(R_{\mathrm{ct}} \times \mathrm{C}_{\mathrm{dl}}\right)$, follows a similar trend as the other two plotted values. The cutoff frequency decreases from butyric $(0.15 \mathrm{~Hz})$ to stearic $(0.05 \mathrm{~Hz})$, indicating a reduction of the kinetic energy of the charge-carrying species as the chain length increases. As chain length extended beyond stearic acid, the trend started to deviate, due to a decrease in the values of double layer capacitance $\left(\mathrm{C}_{\mathrm{dl}}\right)$, while the charge transfer resistance values continued to increase. The values of the circuit elements provide insight into the surface structure of these systems: there likely exists disorder and/or packing defects that detract from the inhibitory quality of the longest two 
chains, which is seen as an effect on the organized structure of the double layer, while the average thickness of the layer continued to increase, which is seen as an increase in the charge transfer resistance.

These hydrogels were used to directly sense $\mathrm{Fe}^{2+}$ by their electrical response; the gels were pre-loaded with ferricyanide and formation of PB within the gels was hypothesized to provide a detectable impedance change. Such hydrogels showed a decrease in the CPE-P values when compared to hydrogels without ferricyanide. Formation of PB sequesters $\mathrm{Fe}^{2+}$, a charged species, which would ordinarily contribute to the double layer capacitance; the observed decrease in the CPE-P value indicates a reduction in the concentration of soluble iron species. As can be seen in Figure 3.5, the \% change in the CPE-P values reflect the relative changes corresponding to each treatment. Plates soaked in ethanol alone showed the greatest decrease in CPE-P value; as there was

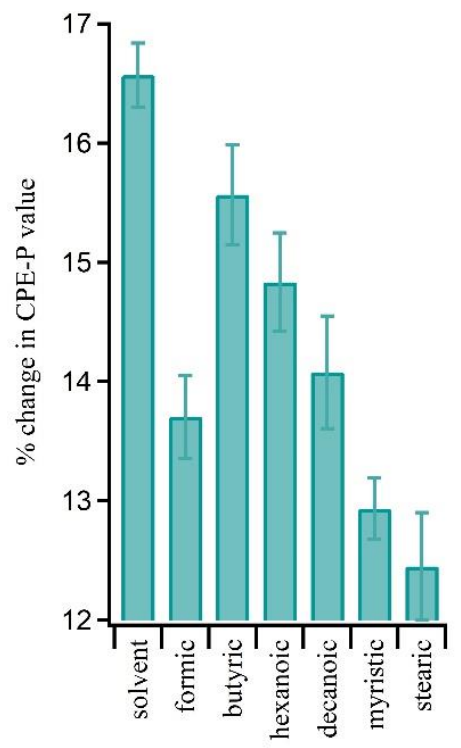

Figure 3.5: Comparison of $\%$ decrease in CPE-P values for various treated panels. The \% change is based on difference between the types of hydrogels used: hydrogels pre-loaded with ferricyanide compared to those without. 
no inhibitor present those panels rapidly evolved $\mathrm{Fe}^{2+}$ at their surfaces. As the chain length of the corrosion inhibitors increased, sequentially smaller changes in the CPE-P values were seen, due to the protective nature of the aliphatic chains inhibiting the production of $\mathrm{Fe}^{2+}$ at the surfaces.

These observations in the colorimetric \& EIS trends suggest that the production of soluble charged iron species from the treated substrates decreases with increasing chain length. This study included longer aliphatic chains than were used in some other studies in the hope of locating a turning point, after which no further gains in the inhibitory powers could be observed. The off-trend cutoff frequency for behenic acid suggests that there begins to be such a turning point at a chain length of 22. Chain lengths exceeding 22 are not practical for this application: they are significantly costlier and they are insoluble in the solvent mixture used, while other nonpolar hydrocarbon solvents have been found to form dimers with fatty acids, rendering them insoluble [195].

To gain a more fundamental understanding of the interactions between fatty acids and steel panels, XPS was utilized. The XPS spectrum of the Fe2 $\mathrm{p}_{3 / 2}$ peak for a representative panel is shown in Figure 3.6. Overall, the XPS spectra for the various inhibitor-treated panels showed a broad peak attributed to $\mathrm{Fe}^{3+}$ with a maximum peak value that ranged from 710.38-710.59 eV (no discernible trend in the $\mathrm{eV}$ for the different chain lengths) and a satellite peak of $\mathrm{Fe}^{3+}\left(\mathrm{Fe}^{3+}{ }_{\text {sat }}\right)$ at $712.66-713.47 \mathrm{eV}$. A distinct peak at $706.65-706.72 \mathrm{eV}$ is attributed to $\mathrm{Fe}(0)$, while the shoulder between $\mathrm{Fe}(0)$ and $\mathrm{Fe}^{3+}$ is attributed to peaks of $\mathrm{Fe}^{2+}(707.4-707.59 \mathrm{eV})$ and (708.1-708.38 eV). The fit is greatly improved by the inclusion of two peaks, likely due to multiple Fe(II) species present on the surfaces [196]. 
The trends in the XPS data (Fig. 3.6b) correlate with those found through the colorimetric and EIS data. The amount of both divalent and trivalent iron species detected decreased with increasing chain length, indicating that less of those species were produced by those plates. While formic acid-treated panels had less $\mathrm{Fe}^{2+}$ and $\mathrm{Fe}(0)$ species compared to panels treated with butyric acid, they had increased $\mathrm{Fe}^{3+}$ peak areas which supports the visual observations made for formic acid -- that it permitted the formation of insoluble corrosion species, a more advanced stage of corrosion.

a)

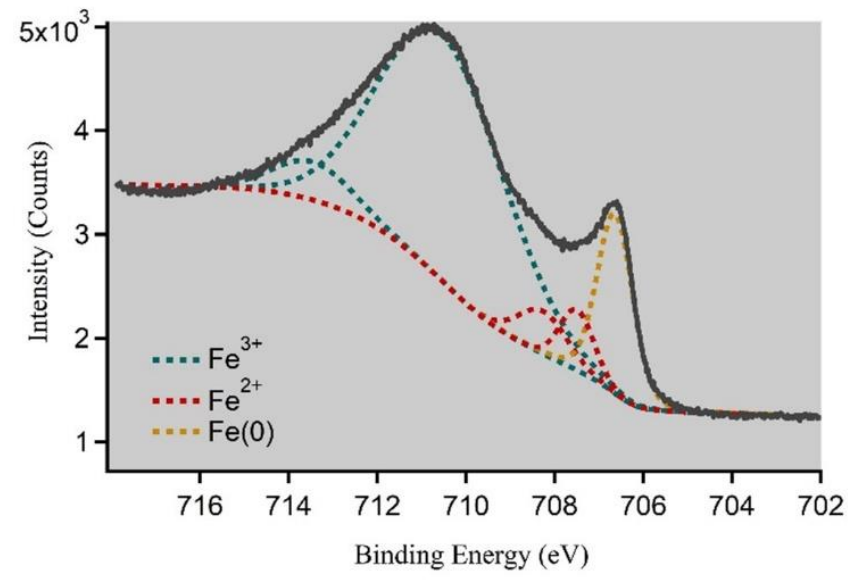

b)

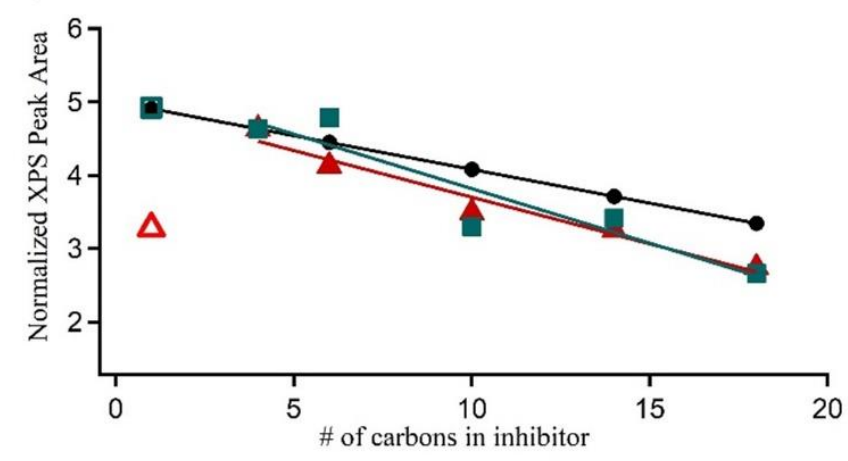

Figure 3.6: a) Fe2p $3 / 2$ portion of XPS plot of a steel plate modified with stearic acid. Solid trace is the spectrum, while the lighter dashed lines depict the peak fits. Peak at $706.64 \mathrm{eV}$ is assigned to $\mathrm{Fe}(0)$, peaks at $707.5 \mathrm{eV}$ and $708.27 \mathrm{eV}$ are assigned to $\mathrm{Fe}^{2+}$, while the peaks at $710.54 \mathrm{eV}$ and $713.47 \mathrm{eV}$ are assigned to $\mathrm{Fe}^{3+}$ and the satellite peak of $\mathrm{Fe}^{3+}$, respectively. b): Black circle markers indicate the expected intensity decrease $(y=-0.092)$, while red square and blue triangle markers indicate the normalized peak areas of $\mathrm{Fe}^{3+}\left(y=-0.1486 x, R^{2}=0.865\right)$ and $\mathrm{Fe}^{2+}\left(y=-0.1271 x, R^{2}=0.9618\right)$, respectively. The open markers indicate the values for formic acid, not used as part of the fit lines. 
In this study a simple quantitative colorimetric technique was used to quickly confirm the presence of nanomole quantities of iron ions. As noted, Prussian blue has many transition metal analogs and, based on prior work, it is likely that these analogs could also be used as other specific ion sensors with colorimetric and impedimetric changes [72]. The impedance characteristics of the corrosion inhibitor thin films, based on equivalent circuits, have similarly shaped trends with the colorimetric data, demonstrating the capability of the dual sensing modes (i.e. spectro-electrochemical detection). The impedimetric data showed that with longer aliphatic chain length there is a decreased cutoff frequency and greater resistance to charge transfer. The CPE-P values suggest that there were decreased available charged species present on the surface as a result, an expected characteristic of an effective corrosion inhibitor. The correlation between chain length and corrosion inhibitor efficacy is also demonstrated in the XPS data, which showed decreased oxidized iron peak areas with increasing chain length. To the authors' knowledge, this is the first published study where quantitative amounts of specific ions solubilized from a corroding metal surface have been directly recorded and visualized via the described portable, low-cost technique utilizing hydrogels. It is hoped that this will serve as a useful study for the development of quantitative benchmarks in corrosion processes. 
Chapter 4: Conclusions \& Final Thoughts

This body of work has successfully demonstrated capture and detection of corrosion-induced metal ions by hydrogel-based sensors. The intelligent nature of the hydrogel response to transition metals produces multiple complementary sensing mechanisms. The colorimetric response is inexpensive, accessible and allows for rapid visual confirmation of ongoing corrosion. The electrical sensing offers a slightly wider dynamic range, a perhaps more desirable linear response (as opposed to logarithimic), and an alternative response if the lighting conditions are not ideal. The calibrated ranges, which are comparable to current sensor literature, are also shown to be suitable for the proposed application of corrosion sensing, based on the ion concentrations collected from a set of steel substrates. The ability to collect these ion concentrations will be considerably useful for the future of corrosion prevention. Beyond these two calibrated sensing methods, volumetric, mechanical and vibrational changes were also seen in the hydrogels and could be further explored in the future.

The sensors' demonstrated ability as substrate ion sensors and their previous success in the field as solid electrolytes make them a strong candidate for in situ work [193, 197]. In comparison to current literature techniques for detecting corrosion, these sensors detect the earliest signs of corrosion, a vast improvement over the current practice of detecting the signs of advanced corrosion damage, when it is far too late to mitigate the damage. The hydrogel sensors were compared to two literature standard techniques; EIS, which is the standard technique for evaluating inhibitor films, and XPS, an advanced technique for determing elemental composition. The correlation with both techniques was 
excellent, indicating that this far cheaper, field-friendly and more accessible technique produces comparable results, while also producing a unique set of information of its own.

The ability of the hydrogels to distinguish between various transition M-HCF complexes based on their absorbances could be leveraged for various applications. In the field of corrosion detection, one application may be to detect specific element-specific flaws in alloys, or to detect metal ions leaching from a coating as it loses its protective quality. Beyond the study of corrosion, the hydrogels have alternate applications (environmental, biomedical) that would benefit from a sensor that can differentiate between ion species in a mixture. With this in mind, one of the primary aspects that future work on this project should focus on is determining and improving upon the exact specificity of the sensors if necessary, through voltammetry, UV-vis, or alternate methods.

Based on the data presented in Chapter 3, the hydrogels demonstrate the ability to "map" regions of a substrate. The colorimetric data, typically visible to the naked eye, has revealed deliberate damage to the substrate, as well as seeming to show defects in the corrosion inhibitor films. While this ability was only peripherally investigated in this body of work, this is an ability that could be utilized to identify which regions are contributing to corrosion and therefore warrants further study. 


\section{References}

1. Office, D.o.D.C.P.a.O., Combating the Pervasive Menace, in Corrosion Comprehension Series, J. Simser, Editor. 2016.

2. G. Koch, J.V., N. Thompson, O. Moghissi, M. Gould \& J. Payer, International Measures of Prevention, Application, and Economics of Corrosion Technologies Study, in IMPACT, G. Jacobson, Editor. 2016, NACE International: Houston, TX.

3. Cicek, V. and B. Al-Numan, Corrosion chemistry. 2011, Wiley; Scrivener: Hoboken, N.J. : Salem, Mass.

4. Pourbaix, M., Lectures on electrochemical corrosion. 1973, New York: Plenum Press.

5. Waseda, Y. and S. Suzuki, Characterization of Corrosion Products on Steel Surfaces. 2006.

6. Ramadan, S., et al., Detection of stress corrosion cracking of high-strength steel used in prestressed concrete structures by acoustic emission technique. Applied Surface Science, 2008. 254(8): p. 2255-2261.

7. ElBatanouny, M.K., et al., Early Corrosion Detection in Prestressed Concrete Girders Using Acoustic Emission. Journal of Materials in Civil Engineering, 2014. 26(3): p. 504-511.

8. Zou, X.T., et al., Nondestructive corrosion detection using fiber optic photoacoustic ultrasound generator. Measurement, 2015. 62: p. 74-80.

9. Li, D.S., et al., Corrosion Monitoring and Evaluation of Reinforced Concrete Structures Utilizing the Ultrasonic Guided Wave Technique. International Journal of Distributed Sensor Networks, 2014.

10. Silva, M.Z., R. Gouyon, and F. Lepoutre, Hidden corrosion detection in aircraft aluminum structures using laser ultrasonics and wavelet transform signal analysis. Ultrasonics, 2003. 41(4): p. 301-305.

11. Yan, Z. and P.B. Nagy, Thermo-optical modulation for improved ultrasonic fatigue crack detection in Ti-6Al-4V. Ndt \& E International, 2000. 33(4): p. 213223.

12. Abouhussien, A.A. and A.A.A. Hassan, Acoustic Emission Monitoring of Corrosion Damage Propagation in Large-Scale Reinforced Concrete Beams. Journal of Performance of Constructed Facilities, 2018. 32(2).

13. Alamin, M., et al., Corrosion detection using low-frequency RFID technology. Insight, 2012. 54(2): p. 72-75.

14. Yang, R.Z., et al., Through coating imaging and nondestructive visualization evaluation of early marine corrosion using electromagnetic induction thermography. Ocean Engineering, 2018. 147: p. 277-288.

15. Roqueta, G., L. Jofre, and M.Q. Feng, Analysis of the Electromagnetic Signature of Reinforced Concrete Structures for Nondestructive Evaluation of Corrosion Damage. Ieee Transactions on Instrumentation and Measurement, 2012. 61(4): p. 1090-1098. 
16. Rumiche, F., J.E. Indacochea, and M.L. Wang, Detection and monitoring of corrosion in structural carbon steels using electromagnetic sensors. Journal of Engineering Materials and Technology-Transactions of the Asme, 2008. 130(3).

17. Almahmoud, S., et al., Detection of Internal Metal Loss in Steel Pipes and Storage Tanks via Magnetic-Based Fiber Optic Sensor. Sensors, 2018. 18(3).

18. Jarvis, R., P. Cawley, and P.B. Nagy, Permanently installed corrosion monitoring using magnetic measurement of current deflection. Structural Health Monitoringan International Journal, 2018. 17(2): p. 227-239.

19. Kouril, M., et al., High sensitivity electrical resistance sensors for indoor corrosion monitoring. Corrosion Engineering Science and Technology, 2013. 48(4): p. 282-287.

20. Karhunen, K., et al., Electrical Resistance Tomography imaging of concrete. Cement and Concrete Research, 2010. 40(1): p. 137-145.

21. Santosleal, E. and R.J. Lopez, SIMULTANEOUS MEASUREMENT OF ACOUSTIC-EMISSION AND ELECTRICAL-RESISTANCE VARIATION IN STRESS-CORROSION CRACKING. Measurement Science and Technology, 1995. 6(2): p. 188-195.

22. Krajci, L. and I. Janotka, Significance of steel electrical resistance method in the evaluation of reinforcement corrosion in cementitious systems. Materiales De Construccion, 2004. 54(274): p. 17-31.

23. Xia, D.H., S.Z. Song, and Y. Behnamian, Detection of corrosion degradation using electrochemical noise (EN): review of signal processing methods for identifying corrosion forms. Corrosion Engineering Science and Technology, 2016. 51(7): p. 527-544.

24. Tan, Y.J., Sensing localised corrosion by means of electrochemical noise detection and analysis. Sensors and Actuators B-Chemical, 2009. 139(2): p. 688698.

25. Tan, Y.J., S. Bailey, and B. Kinsella, The monitoring of the formation and destruction of corrosion inhibitor films using electrochemical noise analysis (ENA). Corrosion Science, 1996. 38(10): p. 1681-1695.

26. Hou, Y., et al., Detection of under deposit corrosion in a CO2 environment by using electrochemical noise and recurrence quantification analysis. Electrochimica Acta, 2018. 274: p. 160-169.

27. Ohki, Y., et al., Detection of Polymer Degradation and Metal Corrosion by Terahertz Imaging Using a Quantum Cascade Laser and a THz Camera. Proceedings of the 2013 Ieee International Conference on Solid Dielectrics (Icsd 2013), Vols 1 and 2, 2013: p. 505-508.

28. Fuse, N., et al., Towards an Improvement in Estimating Rust Degradation in Coated Steels. 2012 37th International Conference on Infrared, Millimeter, and Terahertz Waves (Irmmw-Thz), 2012.

29. Marinetti, S. and V. Vavilov, IR thermographic detection and characterization of hidden corrosion in metals: General analysis. Corrosion Science, 2010. 52(3): p. 865-872.

30. Bagavathiappan, S., et al., Infrared thermography for condition monitoring - A review. Infrared Physics \& Technology, 2013. 60: p. 35-55. 
31. Han, J.S. and J.H. Park, Detection of corrosion steel under an organic coating by infrared photography. Corrosion Science, 2004. 46(4): p. 787-793.

32. Xiaoning, Q. and J.G. Victoria, A Review of Different Sensors Applied to Corrosion Detection and Monitoring. Recent Patents on Corrosion Science (Discontinued), 2011. 1(1): p. 1-7.

33. He, Y.Z., et al., An investigation into eddy current pulsed thermography for detection of corrosion blister. Corrosion Science, 2014. 78: p. 1-6.

34. Uzundal, C.B. and B. Ulgut, Method for visualizing under-coating corrosion utilizing $\mathrm{pH}$ indicators before visible damage. Progress in Organic Coatings, 2018. 122: p. 72-78.

35. Szunerits, S. and D.R. Walt, Aluminum surface corrosion and the mechanism of inhibitors using $\mathrm{pH}$ and metal ion selective imaging fiber bundles. Analytical Chemistry, 2002. 74(4): p. 886-894.

36. Zhao, F., I. Kim, and J. Kim, Fabrication of the Optical Fiber pH Sensor Based on CdSe/ZnS Quantum Dot. Journal of Nanoscience and Nanotechnology, 2014. 14(8): p. 5650-5653.

37. Panova, A.A., P. Pantano, and D.R. Walt, In situ fluorescence imaging of localized corrosion with a pH-sensitive imaging fiber. Anal Chem, 1997. 69(8): p. 1635-41.

38. Pidaparti, R.M., et al., Monitoring the corrosion process of Al alloys through $\mathrm{pH}$ induced fluorescence. Smart Materials and Structures, 2008. 17(1).

39. Smyrl, W.H. and M.A. Alodan, Detection of Localized Corrosion of Aluminum Alloys Using Fluorescence Microscopy. Journal of the Electrochemical Society, 1998. 145(5): p. 1571-1577.

40. McAdam, G., et al., Fiber Optic Sensors for Detection of Corrosion within Aircraft. Structural Health Monitoring, 2005. 4(1): p. 47-56.

41. Luo, X., et al., Preparation of a Smart and Portable Film for in Situ Sensing of Iron Microcorrosion. ACS Applied Materials \& Interfaces, 2018. 10(5): p. 49814985.

42. Roshan, S., A.A.S. Dariani, and J. Mokhtari, Monitoring underlying epoxy-coated St-37 corrosion via 8-hydroxyquinoline as a fluorescent indicator. Applied Surface Science, 2018. 440: p. 880-888.

43. Trinchi, A., et al. Distributed quantum dot sensors for monitoring the integrity of protective aerospace coatings. in Aerospace Conference, 2012 IEEE. 2012.

44. Sibi, M.P. and Z. Zong, Determination of corrosion on aluminum alloy under protective coatings using fluorescent probes. Progress in Organic Coatings, 2003. 47(1): p. 8-15.

45. Materials, A.S.f.T.a., Standard Test Method for Pull-Off Strength of Coatings Using Portable Adhesion Testers. 2017, ASTM International: West Conshohocken, PA.

46. Materials, A.S.f.T.a., Standard Test Method for Adhesion of Organic Coatings by Scrape Adhesion. 2016, ASTM International: West Conshohocken, PA.

47. Stumpel, J.E., et al., Stimuli-Responsive Materials Based on Interpenetrating Polymer Liquid Crystal Hydrogels. Advanced Functional Materials, 2015. 25(22): p. 3314-3320. 
48. Scott, L.J., et al., Self-assembling electroactive hydrogels for flexible display technology. Journal of Physics: Condensed Matter, 2010. 22(49): p. 494105.

49. Tellis, J.C., et al., Relative Humidity Sensors Based on an Environment-Sensitive Fluorophore in Hydrogel Films. Analytical Chemistry, 2011. 83(3): p. 928-932.

50. Zhao, Y., et al., Superabsorbent hydrogels from poly(aspartic acid) with salt-, temperature- and pH-responsiveness properties. Polymer, 2005. 46(14): p. 53685376.

51. Sivanantham, M., et al., Stimulus response and molecular structural modification of polyacrylamide gel in nitric acid: A study by Raman, FTIR, and photoluminescence techniques. Journal of Polymer Science Part B: Polymer Physics, 2008. 46(7): p. 710-720.

52. Orthner, M.P., et al., Development, Fabrication, and Characterization of Hydrogel Based Piezoresistive Pressure Sensors with Perforated Diaphragms. Sens Actuators A Phys, 2010. 161(1-2): p. 29-38.

53. Cai, W., et al., C2-Symmetric Benzene-based Low Molecular Weight Hydrogel Modified Electrode for Highly Sensitive Detection of Copper Ions. Electrochimica Acta, 2015. 169: p. 424-432.

54. Arnold, F.H., W.G. Zheng, and A.S. Michaels, A membrane-moderated, conductimetric sensor for the detection and measurement of specific organic solutes in aqueous solutions. Journal of Membrane Science, 2000. 167(2): p. 227239.

55. Khan, M., S. Schuster, and M. Zharnikov, Effect of Humidity on Electrical Conductivity of Pristine and Nanoparticle-Loaded Hydrogel Nanomembranes. Journal of Physical Chemistry C, 2015. 119(25): p. 14427-14433.

56. Zhang, Y.C. and C. Ji, Electro-Induced Covalent Cross-Linking of Chitosan and Formation of Chitosan Hydrogel Films: Its Application as an Enzyme Immobilization Matrix for Use in a Phenol Sensor. Analytical Chemistry, 2010. 82(12): p. 5275-5281.

57. Brahim, S., D. Narinesingh, and A. Guiseppi-Elie, Polypyrrole-hydrogel composites for the construction of clinically important biosensors. Biosensors \& Bioelectronics, 2002. 17(1-2): p. 53-59.

58. Koide, S. and K. Yokoyama, Electrochemical characterization of an enzyme electrode based on a ferrocene-containing redox polymer. Journal of Electroanalytical Chemistry, 1999. 468(2): p. 193-201.

59. Park, J.S., et al., Selective response of cyclodextrin-dye hydrogel to metal ions. Journal of Inclusion Phenomena and Macrocyclic Chemistry, 2011. 71(1): p. 7986.

60. Wang, H., et al., Responsive polymer-fluorescent carbon nanoparticle hybrid nanogels for optical temperature sensing, near-infrared light-responsive drug release, and tumor cell imaging. Nanoscale, 2014. 6(13): p. 7443-52.

61. Taşdelen, B., et al., Preparation of poly(N-isopropylacrylamide/itaconic acid) copolymeric hydrogels and their drug release behavior. International Journal of Pharmaceutics, 2004. 278(2): p. 343-351.

62. Wang, Q., et al., Preparation and swelling properties of pH-sensitive composite hydrogel beads based on chitosan-g-poly (acrylic acid)/vermiculite and sodium 
alginate for diclofenac controlled release. International Journal of Biological Macromolecules, 2010. 46(3): p. 356-362.

63. Shakhsher, M.Z., et al., An Optical Chemical Sensor Based on Swellable Dicarboxylate Functionalized Polymer Microspheres for $p H$ Copper and Calcium Determination. Microchimica Acta, 2004. 144(1): p. 147-153.

64. Lin, Q., et al., Double metal ions competitively control the guest-sensing process: a facile approach to stimuli-responsive supramolecular gels. Chemistry, 2014. 20(36): p. 11457-62.

65. Lin, H., et al., DNAzyme crosslinked hydrogel: a new platform for visual detection of metal ions. Chemical Communications, 2011. 47(33): p. 9312-9314.

66. Lee, Y.J., S.A. Pruzinsky, and P.V. Braun, Glucose-sensitive inverse opal hydrogels: Analysis of optical diffraction response. Langmuir, 2004. 20(8): p. 3096-3106.

67. Valle, H., J. Sanchez, and B.L. Rivas, Poly(N-vinylpyrrolidone-co-2-acrylamido2-methylpropanesulfonate sodium): Synthesis, Characterization, and its Potential Application for the Removal of Metal Ions from Aqueous Solution. Journal of Applied Polymer Science, 2015. 132(2).

68. Souda, P. and L. Sreejith, Poly (Acrylate-Acrylic acid-co-Maleic acid) hydrogel: A Cost Effective and Efficient Method for Removal of Metal Ions from Water. Separation Science and Technology, 2013. 48(18): p. 2795-2803.

69. Rivas, B.L., et al., Metal ion uptake properties of acrylamide derivative resins. Macromolecular Chemistry and Physics, 2001. 202(3): p. 443-447.

70. Kandile, N.G. and A.S. Nasr, Environment friendly modified chitosan hydrogels as a matrix for adsorption of metal ions, synthesis and characterization. Carbohydrate Polymers, 2009. 78(4): p. 753-759.

71. Li, W., et al., Synthesis and characterisation of a polyacrylamide-polyacrylic acid copolymer hydrogel for environmental analysis of $\mathrm{Cu}$ and $\mathrm{Cd}$. Reactive and Functional Polymers, 2002. 52(1): p. 31-41.

72. Price, C., J. Carroll, and T.L. Clare, Chemoresistive and photonic hydrogel sensors of transition metal ions via Hofmeister series principles. Sensors and Actuators B: Chemical, 2018. 256: p. 870-877.

73. Voiculescu, I., et al., Micropreconcentrator for enhanced trace detection of explosives and chemical agents. Ieee Sensors Journal, 2006. 6(5): p. 1094-1104.

74. Maizels, M., et al., Novel Spectroelectrochemical Sensor for Ferrocyanide in Hanford Waste Simulant, in Nuclear Site Remediation. 2000, American Chemical Society. p. 364-378.

75. Buenger, D., F. Topuz, and J. Groll, Hydrogels in sensing applications. Progress in Polymer Science, 2012. 37(12): p. 1678-1719.

76. Pizzorusso, G., et al., Physicochemical Characterization of Acrylamide/Bisacrylamide Hydrogels and Their Application for the Conservation of Easel Paintings. Langmuir, 2012. 28(8): p. 3952-3961.

77. Kunz, W., J. Henle, and B.W. Ninham, 'Zur Lehre von der Wirkung der Salze' (about the science of the effect of salts): Franz Hofmeister's historical papers. Current Opinion in Colloid \& Interface Science, 2004. 9(1-2): p. 19-37. 
78. Hofmeister, F., Zur Lehre von der Wirkung der Salze. Archiv für experimentelle Pathologie und Pharmakologie, 1888. 25(1): p. 1-30.

79. Collins, K.D., Ion hydration: Implications for cellular function, polyelectrolytes, and protein crystallization. Biophysical Chemistry, 2006. 119(3): p. 271-281.

80. Collins, K.D., Ions from the Hofmeister series and osmolytes: effects on proteins in solution and in the crystallization process. Methods, 2004. 34(3): p. 300-11.

81. Salis, A. and B.W. Ninham, Models and mechanisms of Hofmeister effects in electrolyte solutions, and colloid and protein systems revisited. Chem Soc Rev, 2014. 43(21): p. 7358-77.

82. Tansel, B., Significance of thermodynamic and physical characteristics on permeation of ions during membrane separation: Hydrated radius, hydration free energy and viscous effects. Separation and Purification Technology, 2012. 86: p. 119-126.

83. Vlachy, N., et al., Hofmeister series and specific interactions of charged headgroups with aqueous ions. Advances in Colloid and Interface Science, 2009. 146(1-2): p. 42-47.

84. Strauss, U.P. and Y.P. Leung, Volume Changes as a Criterion for Site Binding of Counterions by Polyelectrolytes1. Journal of the American Chemical Society, 1965. 87(7): p. 1476-1480.

85. Reichenberg, D., K.W. Pepper, and D.J. McCauley, PROPERTIES OF IONEXCHANGE RESINS IN RELATION TO THEIR STRUCTURE .2. RELATIVE AFFINITIES. Journal of the Chemical Society, 1951(FEB): p. 493-499.

86. Hubicki, Z. and D. Kołodyńska, Selective Removal of Heavy Metal Ions from Waters and Waste Waters Using Ion Exchange Methods. 2012: INTECH Open Access Publisher.

87. Horkay, F., I. Tasaki, and P.J. Basser, Effect of Monovalent-Divalent Cation Exchange on the Swelling of Polyacrylate Hydrogels in Physiological Salt Solutions. Biomacromolecules, 2001. 2(1): p. 195-199.

88. Henderson, K.J., et al., Ionically Cross-Linked Triblock Copolymer Hydrogels with High Strength. Macromolecules, 2010. 43(14): p. 6193-6201.

89. Wall, F.T. and J.W. Drenan, Gelation of polyacrylic acid by divalent cations. Journal of Polymer Science, 1951. 7(1): p. 83-88.

90. Wall, F.T. and S.J. Gill, INTERACTION OF CUPRIC IONS WITH POLYACRYLIC ACID. Journal of Physical Chemistry, 1954. 58(12): p. 11281130.

91. Liu, B., et al., In situ electrical conductivity measurements of $\mathrm{H} 2 \mathrm{O}$ under static pressure up to 28 GPa. Physics Letters A, 2016. 380(37): p. 2979-2983.

92. de Tacconi, N.R., K. Rajeshwar, and R.O. Lezna, Metal Hexacyanoferrates: Electrosynthesis, in Situ Characterization, and Applications. Chemistry of Materials, 2003. 15(16): p. 3046-3062.

93. Padigi, S.K., Multivalent Rechargeable Batteries, in Department of Physics. 2015, Portland State University: Portland, OR. p. 1-169.

94. García-Jareño, J.J., J. Navarro-Laboulais, and F. Vicente, Electrochemical study of Nafion membranes/Prussian blue films on ITO electrodes. Electrochimica Acta, 1996. 41(17): p. 2675-2682. 
95. Boutry, S., et al., How to quantify iron in an aqueous or biological matrix: a technical note. Contrast Media \& Molecular Imaging, 2009. 4(6): p. 299-304.

96. Karyakin, A.A., Prussian Blue and its analogues: Electrochemistry and analytical applications. Electroanalysis, 2001. 13(10): p. 813-819.

97. Keggin, J.F. and F.D. Miles, Structures and Formula of the Prussian Blues and Related Compounds. Nature, 1936. 137: p. 577.

98. Herren, F., et al., Neutron diffraction study of Prussian Blue, $\mathrm{Fe} 4[\mathrm{Fe}(\mathrm{CN}) 6] 3 . x \mathrm{H} 2 \mathrm{O}$. Location of water molecules and long-range magnetic order. Vol. 19. 1980. 956-959.

99. Robin, M.B., The Color and Electronic Configurations of Prussian Blue. Inorganic Chemistry, 1962. 1(2): p. 337-342.

100. Itaya, K., I. Uchida, and V.D. Neff, Electrochemistry of polynuclear transition metal cyanides: Prussian blue and its analogues. Accounts of Chemical Research, 1986. 19(6): p. 162-168.

101. Shores, M.P., L.G. Beauvais, and J.R. Long, Cluster-Expanded Prussian Blue Analogues. Journal of the American Chemical Society, 1999. 121(4): p. 775-779.

102. Byrne, M.E., K. Park, and N.A. Peppas, Molecular imprinting within hydrogels. Advanced Drug Delivery Reviews, 2002. 54(1): p. 149-161.

103. Gao, L.T., C.J. Seliskar, and W.R. Heineman, Spectroelectrochemical sensing based on multimode selectivity simultaneously achievable in a single device. 4. Sensing with poly(vinyl alcohol)-polyelectrolyte blend modified optically transparent electrodes. Analytical Chemistry, 1999. 71(18): p. 4061-4068.

104. Gawel, K., et al., Responsive Hydrogels for Label-Free Signal Transduction within Biosensors. Sensors, 2010. 10(5): p. 4381-4409.

105. Squires, T.M., R.J. Messinger, and S.R. Manalis, Making it stick: convection, reaction and diffusion in surface-based biosensors. Nature Biotechnology, 2008. 26(4): p. 417-426.

106. Peppas, N.A., et al., Hydrogels in biology and medicine: From molecular principles to bionanotechnology. Advanced Materials, 2006. 18(11): p. 13451360 .

107. Holtz, J.H. and S.A. Asher, Polymerized colloidal crystal hydrogel films as intelligent chemical sensing materials. Nature, 1997. 389(6653): p. 829-832.

108. Gerlach, G., et al., Chemical and pH sensors based on the swelling behavior of hydrogels. Sensors and Actuators B-Chemical, 2005. 111: p. 555-561.

109. Gogoi, N., et al., Carbon Dots Rooted Agarose Hydrogel Hybrid Platform for Optical Detection and Separation of Heavy Metal Ions. Acs Applied Materials \& Interfaces, 2015. 7(5): p. 3058-3067.

110. Nishiyabu, R., H. Kobayashi, and Y. Kubo, Dansyl-containing boronate hydrogel film as fluorescent chemosensor of copper ions in water. RSC Advances, 2012. 2(16): p. 6555-6561.

111. Rounds, R.M., et al., Microporated PEG spheres for fluorescent analyte detection. J Fluoresc, 2007. 17(1): p. 57-63.

112. Martínez, M.V., et al., A colorimetric iron sensor based on the partition of phenanthroline complexes into polymeric hydrogels. Combinatorial synthesis and 
high throughput screening of the hydrogel matrix. Sensors and Actuators B: Chemical, 2017. 241: p. 19-32.

113. Ho, C.K., et al., Overview of sensors and needs for environmental monitoring. Sensors, 2005. 5(1-2): p. 4-37.

114. Carter, K.P., A.M. Young, and A.E. Palmer, Fluorescent Sensors for Measuring Metal Ions in Living Systems. Chemical Reviews, 2014. 114(8): p. 4564-4601.

115. Tchounwou, P.B., et al., Heavy Metals Toxicity and the Environment. EXS, 2012. 101: p. 133-164.

116. Ojwang, D.O., et al., Structure Characterization and Properties of K-Containing Copper Hexacyanoferrate. Inorganic Chemistry, 2016. 55(12): p. 5924-5934.

117. Bartos, B., et al., Adsorption of Cs-137 on titanium ferrocyanide and transformation of the sorbent to lithium titanate: a new method for long term immobilization of Cs-137. Journal of Radioanalytical and Nuclear Chemistry, 2014. 302(1): p. 513-516.

118. Lin, M.S., T.F. Tseng, and W.C. Shih, Chromium(III) hexacyanoferrate(II)-based chemical sensor for the cathodic determination of hydrogen peroxide. Analyst, 1998. 123(1): p. 159-163.

119. Kandanapitiye, M.S., et al., Gallium Analogue of Soluble Prussian Blue KGa $\mathrm{Fe}(\mathrm{CN})(6)$ center dot $\mathrm{nH}(2) \mathrm{O}$ : Synthesis, Characterization, and Potential Biomedical Applications. Inorganic Chemistry, 2013. 52(6): p. 2790-2792.

120. Gil, D.M., et al., Crystal structure refinement, spectroscopic study and magnetic properties of yttrium hexacyanoferrate (III). Journal of Molecular Structure, 2011. 1003(1-3): p. 129-133.

121. Liu, S.-Q., Y. Chen, and H.-Y. Chen, Studies of spectroscopy and cyclic voltammetry on a zirconium hexacyanoferrate modified electrode. Journal of Electroanalytical Chemistry, 2001. 502(1-2): p. 197-203.

122. Noroozifar, M., M. Khorasani-Motlagh, and A. Taheri, Preparation of silver hexacyanoferrate nanoparticles and its application for the simultaneous determination of ascorbic acid, dopamine and uric acid. Talanta, 2010. 80(5): p. 1657-1664.

123. Mal'arova, M., et al., Polymeric $\{\mathrm{Cd}(\mathrm{en})\}(3)(\mathrm{Fe}(\mathrm{CN})(6)\}(2)$ center dot $4 \mathrm{H}(2) \mathrm{O}$ : Preparation, crystal structure and characterization (en=1,2-diaminoethane). Zeitschrift Fur Anorganische Und Allgemeine Chemie, 2006. 632(3): p. 495-500.

124. Liu, S.Q. and H.Y. Chen, Spectroscopic and voltammetric studies on a lanthanum hexacyanoferrate modified electrode. Journal of Electroanalytical Chemistry, 2002. 528(1-2): p. 190-195.

125. Gil, D.M., et al., Lead hexacyanoferrate(II) tetrahydrate: Crystal structure, FTIR spectroscopy and thermal decomposition studies. Polyhedron, 2012. 33(1): p. 450-455.

126. Liu, S., et al., Platinum hexacyanoferrate: A novel Prussian Blue analogue with stable electroactive properties. Journal of Electroanalytical Chemistry, 1997. 426(1): p. 27-30.

127. Mullica, D.F., H.O. Perkins, and E.L. Sappenfield, Synthesis, spectroscopic studies, and crystal and molecular structure of bismuth hexacyanoferrate(III) tetrahydrate, $\mathrm{BiFe}(\mathrm{CN}) 6 \cdot 4 \mathrm{H} 2 \mathrm{O}$. Inorganica Chimica Acta, 1988. 142(1): p. 9-12. 
128. Agrisuelas, J., J.J. García-Jareño, and F. Vicente, Identification of Processes Associated with Different Iron Sites in the Prussian Blue Structure by in Situ Electrochemical, Gravimetric, and Spectroscopic Techniques in the dc and ac Regimes. The Journal of Physical Chemistry C, 2012. 116(2): p. 1935-1947.

129. Retter, U., et al., On the impedance of potassium nickel(II) hexacyanoferrate(II) composite electrodes - the generalization of the Randles model referring to inhomogeneous electrode materials. Journal of Electroanalytical Chemistry, 2003. 546: p. 87-96.

130. Garciajareno, J.J., et al., IMPEDANCE ANALYSIS OF PRUSSIAN-BLUE FILMS DEPOSITED ON ITO ELECTRODES. Electrochimica Acta, 1995. 40(9): p. 1113-1119.

131. Yang, L., Y. Li, and G.F. Erf, Interdigitated Array microelectrode-based electrochemical impedance immunosensor for detection of Escherichia coli O157:H7. Anal Chem, 2004. 76(4): p. 1107-13.

132. Gębala, M. and W. Schuhmann, Controlled Orientation of DNA in a Binary SAM as a Key for the Successful Determination of DNA Hybridization by Means of Electrochemical Impedance Spectroscopy. ChemPhysChem, 2010. 11(13): p. 2887-2895.

133. Kulesza, P.J., et al., Electrochemical charging, countercation accommodation, and spectrochemical identity of microcrystalline solid cobalt hexacyanoferrate. Journal of Physical Chemistry B, 1998. 102(11): p. 1870-1876.

134. Cacace, M.G., E.M. Landau, and J.J. Ramsden, The Hofmeister series: salt and solvent effects on interfacial phenomena. Q Rev Biophys, 1997. 30(3): p. 241-77.

135. Collins, K.D. and M.W. Washabaugh, The Hofmeister effect and the behaviour of water at interfaces. Q Rev Biophys, 1985. 18(4): p. 323-422.

136. Haverd, V.E. and G.G. Warr, Cation Selectivity at Air/Anionic Surfactant Solution Interfaces. Langmuir, 2000. 16(1): p. 157-160.

137. Strauss, U.P., Short-Range Interactions Between Polyions and Small Ions, in Polyelectrolytes: Papers Initiated by a NATO Advanced Study Institute on Charged and Reactive Polymers held in France, June 1972, E. Sélégny, M. Mandel, and U.P. Strauss, Editors. 1974, Springer Netherlands: Dordrecht. p. 7985.

138. England, A.H. and T.L. Clare, Synthesis and Characterization of Flexible Hydrogel Electrodes for Electrochemical Impedance Measurements of Protective Coatings on Metal Sculptures. Electroanalysis, 2014. 26(5): p. 1059-1067.

139. Roccaro, P., M. Yan, and G.V. Korshin, Use of log-transformed absorbance spectra for online monitoring of the reactivity of natural organic matter. Water Research, 2015. 84: p. 136-143.

140. Wu, S., et al., Colorimetric Aptasensor Based on Enzyme for the Detection of Vibrio parahemolyticus. Journal of Agricultural and Food Chemistry, 2015. 63(35): p. 7849-7854.

141. Fengqiang Wang, D.D., Daisy Richardson \& Alexandre Ambrogelly, The Comparison of Chemiluminescent- and Colorimetric-detection Based ELISA for Chinese Hamster Ovary Host Cell Proteins Quantification in Biotherapeutics. Journal of Bioprocessing and Biotechniques 2013. 3(136). 
142. Zamora, L.L., A.M. Mellado Romero, and J.M. Calatayud, Quantitative Colorimetric Analysis of Some Inorganic Salts Using Digital Photography. Analytical Letters, 2011. 44(9): p. 1674-1682.

143. Dong, J., Y. Ozaki, and K. Nakashima, Infrared, Raman, and Near-Infrared Spectroscopic Evidence for the Coexistence of Various Hydrogen-Bond Forms in Poly(acrylic acid). Macromolecules, 1997. 30(4): p. 1111-1117.

144. Torii, H., T. Tatsumi, and M. Tasumi, Effects of hydration on the structure, vibrational wavenumbers, vibrational force field and resonance raman intensities of N-methylacetamide. Journal of Raman Spectroscopy, 1998. 29(6): p. 537-546.

145. Sun, Q., Raman spectroscopic study of the effects of dissolved $\mathrm{NaCl}$ on water structure. Vibrational Spectroscopy, 2012. 62: p. 110-114.

146. Funke, S. and H. Wackerbarth, The role of the dielectric environment in surfaceenhanced Raman scattering on the detection of a 4-nitrothiophenol monolayer. Journal of Raman Spectroscopy, 2013. 44(7): p. 1010-1013.

147. Miura, T., H. Takeuchi, and I. Harada, Tryptophan Raman bands sensitive to hydrogen bonding and side-chain conformation. Journal of Raman Spectroscopy, 1989. 20(10): p. 667-671.

148. Lowry, S.R. and K.A. Mauritz, An investigation of ionic hydration effects in perfluorosulfonate ionomers by Fourier transform infrared spectroscopy. Journal of the American Chemical Society, 1980. 102(14): p. 4665-4667.

149. Hongsirikarn, K., et al., Effect of cations $(\mathrm{Na}+\mathrm{Ca}+, \mathrm{Fe} 3+)$ on the conductivity of a Nafion membrane. Journal of Power Sources, 2010. 195(21): p. 7213-7220.

150. Pourjavadi, A., M.S. Amini-Fazl, and H. Hosseinzadeh, Partially hydrolyzed crosslinked alginate-graft-polymethacrylamide as a novel biopolymer-based superabsorbent hydrogel having pH-responsive properties. Macromolecular Research, 2005. 13(1): p. 45-53.

151. Zhu, Q., C.W. Barney, and K.A. Erk, Effect of ionic crosslinking on the swelling and mechanical response of model superabsorbent polymer hydrogels for internally cured concrete. Materials and Structures, 2015. 48(7): p. 2261-2276.

152. Keggin, M., Structures and Formula of the Prussian Blues and Related Compounds. Nature, 1936.

153. Samain, L., et al., Relationship between the Synthesis of Prussian Blue Pigments, Their Color, Physical Properties, and Their Behavior in Paint Layers. The Journal of Physical Chemistry C, 2013. 117(19): p. 9693-9712.

154. Levy, L.Y., M. Muzzi, and H.D. Hurwitz, INFRARED INVESTIGATION OF IONIC HYDRATION IN ION-EXCHANGE MEMBRANES .2. ALKALINE-EARTH SALTS OF GRAFTED POLYSTYRENE SULFONIC-ACID MEMBRANES. Journal of the Chemical Society-Faraday Transactions I, 1982. 78: p. 17-28.

155. Kujawski, W., Q.T. Nguyen, and J. Neel, Infrared Investigations of Sulfonated Ionomer Membranes. I. Water-Alcohol Compositions and Counterions Effects. Journal of Applied Polymer Science, 1992. 44(6): p. 951-958.

156. Zhu, H. and X. Yao, Synthesis and Characterization of Poly(Acrylamide-co-2Acrylamido-2-Methylpropane Sulfonic Acid)/Kaolin Superabsorbent Composite. Journal of Macromolecular Science Part a-Pure and Applied Chemistry, 2013. 50(2): p. 175-184. 
157. Barsan, M.M., et al., High-pressure studies of the micro-Raman spectra of iron cyanide complexes: Prussian blue $(\mathrm{Fe} 4[\mathrm{Fe}(\mathrm{CN}) 6] 3)$, potassium ferricyanide ( $\mathrm{K3}[\mathrm{Fe}(\mathrm{CN}) 6])$, and sodium nitroprusside $(\mathrm{Na2}[\mathrm{Fe}(\mathrm{CN}) 5(\mathrm{NO})] \cdot 2 \mathrm{H} 2 \mathrm{O})$. Journal of Raman Spectroscopy, 2011. 42(9): p. 1820-1824.

158. Malinauskas, A., et al., Evaluation of operational stability of Prussian blue-and cobalt hexacyanoferrate-based amperometric hydrogen peroxide sensors for biosensing application. Materials Science \& Engineering C-Biomimetic and Supramolecular Systems, 2004. 24(4): p. 513-519.

159. Samain, L., et al., Redox reactions in Prussian blue containing paint layers as a result of light exposure. Journal of Analytical Atomic Spectrometry, 2013. 28(4): p. 524-535.

160. Baioni, A.P., et al., Synthesis and Characterization of Copper Hexacyanoferrate Nanoparticles for Building Up Long-Term Stability Electrochromic Electrodes. Langmuir, 2007. 23(12): p. 6796-6800.

161. Lisowska-Oleksiak, A., et al., Ex situ XANES, XPS and Raman studies of poly(3,4-ethylenedioxythiophene) modified by iron hexacyanoferrate. Synthetic Metals, 2010. 160(11-12): p. 1234-1240.

162. Agarwala, V.S., P.L. Reed, and S. Ahmad, Corrosion Detection and Monitoring A Review, in CORROSION 2000. 2000, NACE International: Orlando, Florida.

163. Huthwaite, P., et al., Mode Selection for Corrosion Detection in Pipes and Vessels via Guided Wave Tomography. Ieee Transactions on Ultrasonics Ferroelectrics and Frequency Control, 2013. 60(6): p. 1165-1177.

164. Breugelmans, T., et al., Odd random phase multisine EIS as a detection method for the onset of corrosion of coated steel. Electrochemistry Communications, 2010. 12(1): p. 2-5.

165. Hosseini, S. and A.A. Lakis, Application of time-frequency analysis for automatic hidden corrosion detection in a multilayer aluminum structure using pulsed eddy current. Ndt \& E International, 2012. 47: p. 70-79.

166. Schonberger, A., et al., Non-destructive detection of corrosion applied to steel and galvanized steel coated with organic paints by the pulsed phase thermography. Materials and Corrosion-Werkstoffe Und Korrosion, 2012. 63(3): p. 195-199.

167. Buser, H.J., et al., CRYSTAL-STRUCTURE OF PRUSSIAN BLUE - FE4 FE(CN)6 3.XH2O. Inorganic Chemistry, 1977. 16(11): p. 2704-2710.

168. Podkoscielna, B., A. Bartnicki, and B. Gawdzik, New crosslinked hydrogels derivatives of 2-hydroxyethyl methacrylate: Synthesis, modifications and properties. Express Polymer Letters, 2012. 6(9): p. 759-771.

169. Nickerson, M.T., et al., Some physical properties of crosslinked gelatinmaltodextrin hydrogels. Food Hydrocolloids, 2006. 20(7): p. 1072-1079.

170. Guvendiren, M., S. Yang, and J.A. Burdick, Swelling-Induced Surface Patterns in Hydrogels with Gradient Crosslinking Density. Advanced Functional Materials, 2009. 19(19): p. 3038-3045.

171. Peppas, N.A. and D.S. Van Blarcom, Hydrogel-based biosensors and sensing devices for drug delivery. Journal of Controlled Release, 2016. 240: p. 142-150. 
172. Sekitani, T., et al., Ultraflexible organic amplifier with biocompatible gel electrodes. Nature Communications, 2016. 7: p. 11425.

173. Saheb, A., M. Josowicz, and J. Janata, Chemically Sensitive Field-Effect Transistor with Polyaniline-Ionic Liquid Composite Gate. Analytical Chemistry, 2008. 80(11): p. 4214-4219.

174. Sapra, K.T. and H. Bayley, Lipid-coated hydrogel shapes as components of electrical circuits and mechanical devices. Scientific Reports, 2012. 2: p. 848.

175. Buckholtz, G.A. and E.S. Gawalt, Effect of Alkyl Chain Length on Carboxylic Acid SAMs on Ti-6Al-4V. Materials, 2012. 5(7): p. 1206.

176. Raman, A., et al., Formation of Self-Assembled Monolayers of Alkylphosphonic Acid on the Native Oxide Surface of SS316L. Langmuir, 2006. 22(15): p. 64696472.

177. Shustak, G., A.J. Domb, and D. Mandler, Preparation and Characterization of nAlkanoic Acid Self-Assembled Monolayers Adsorbed on 316L Stainless Steel. Langmuir, 2004. 20(18): p. 7499-7506.

178. Ghareba, S. and S. Omanovic, Interaction of 12-aminododecanoic acid with a carbon steel surface: Towards the development of 'green' corrosion inhibitors. Corrosion Science, 2010. 52(6): p. 2104-2113.

179. Ito, E., et al., Chain length dependence of adsorption structure of $\mathrm{COOH}$ terminated alkanethiol SAMs on Au(111). Applied Surface Science, 2005. 244(1): p. 584-587.

180. Bedford, E., et al., An experimental and theoretical approach to investigate the effect of chain length on aminothiol adsorption and assembly on gold. Chemistry, 2015. 21(41): p. 14555-61.

181. Gericke, A. and H. Huhnerfuss, IN-SITU INVESTIGATION OF SATURATED LONG-CHAIN FATTY-ACIDS AT THE AIR-WATER-INTERFACE BY EXTERNAL INFRARED REFLECTION-ABSORPTION SPECTROMETRY. Journal of Physical Chemistry, 1993. 97(49): p. 12899-12908.

182. Quiñones, R. and E.S. Gawalt, Study of the Formation of Self-Assembled Monolayers on Nitinol. Langmuir, 2007. 23(20): p. 10123-10130.

183. Kanicky, J.R., et al., Cooperativity among Molecules at Interfaces in Relation to Various Technological Processes: Effect of Chain Length on the pKa of Fatty Acid Salt Solutions. Langmuir, 2000. 16(1): p. 172-177.

184. Touwslager, F.J. and A.H.M. Sondag, ORDER AND DISORDER IN NALKYLCARBOXYLIC ACID MONOLAYERS - CHAIN-LENGTH DEPENDENCE AND LATERAL INTERACTION EFFECTS. Langmuir, 1994. 10(4): p. 10281033.

185. Spori, D.M., et al., Influence of Alkyl Chain Length on Phosphate Self-Assembled Monolayers. Langmuir, 2007. 23(15): p. 8053-8060.

186. Muro, M., Y. Itoh, and T. Hasegawa, A Conformation and Orientation Model of the Carboxylic Group of Fatty Acids Dependent on Chain Length in a Langmuir Monolayer Film Studied by Polarization-Modulation Infrared Reflection Absorption Spectroscopy. The Journal of Physical Chemistry B, 2010. 114(35): p. 11496-11501. 
187. Metoki, N., et al., Preparation and Characterization of Alkylphosphonic Acid Self-Assembled Monolayers on Titanium Alloy by Chemisorption and Electrochemical Deposition. Langmuir, 2014. 30(23): p. 6791-6799.

188. Hosseinpour, S., C.M. Johnson, and C. Leygraf, Alkanethiols as Inhibitors for the Atmospheric Corrosion of Copper Induced by Formic Acid: Effect of Chain Length. Journal of the Electrochemical Society, 2013. 160(6): p. C270-C276.

189. Allara, D.L. and R.G. Nuzzo, Spontaneously organized molecular assemblies. 1. Formation, dynamics, and physical properties of n-alkanoic acids adsorbed from solution on an oxidized aluminum surface. Langmuir, 1985. 1(1): p. 45-52.

190. Alagta, A., et al., Corrosion protection properties of hydroxamic acid selfassembled monolayer on carbon steel. Corrosion Science, 2008. 50(6): p. 16441649.

191. Laibinis, P.E., C.D. Bain, and G.M. Whitesides, Attenuation of photoelectrons in monolayers of n-alkanethiols adsorbed on copper, silver, and gold. The Journal of Physical Chemistry, 1991. 95(18): p. 7017-7021.

192. Wallart, X., C. Henry de Villeneuve, and P. Allongue, Truly Quantitative XPS Characterization of Organic Monolayers on Silicon: Study of Alkyl and Alkoxy Monolayers on H-Si(111). Journal of the American Chemical Society, 2005. 127(21): p. 7871-7878.

193. Hosbein, K.N., et al., Measuring Sheet Resistances of Dielectrics Using CoPlanar Hydrogel Electrochemical Cells with Practical Applications to Characterize the Protective Quality of Paints on Sculptures. Electroanalysis, 2017. 29(5): p. 1377-1387.

194. Aleksander, Ś, S. Mikael, and J. Gillis, Double-layer capacitance measurements of self-assembled layers on gold electrodes. Electroanalysis, 1992. 4(10): p. 921928.

195. Calvo, B. and E.A. Cepeda, Solubilities of Stearic Acid in Organic Solvents and in Azeotropic Solvent Mixtures. Journal of Chemical \& Engineering Data, 2008. 53(3): p. 628-633.

196. Grosvenor, A.P., et al., Investigation of multiplet splitting of Fe $2 p$ XPS spectra and bonding in iron compounds. Surface and Interface Analysis, 2004. 36(12): p. 1564-1574.

197. England, A., et al., Assessing the Protective Quality of Wax Coatings on Bronze Sculptures Using Hydrogel Patches in Impedance Measurements. Coatings, 2016. 6(4): p. 45. 
Appendix: Video Files

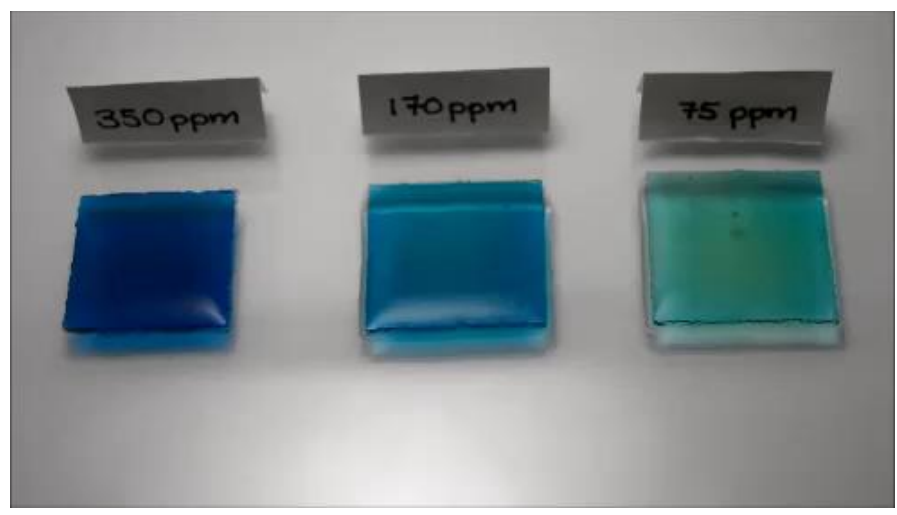

Video 1. Depicts the process of forming Prussian blue within the hydrogels. The concentrations shown are the ppm within the hydrogel.

Filesize: $1788 \mathrm{~KB}$

Filetype: Audio Video Interleaved (.avi)

Possible required software: Free VLC media player.

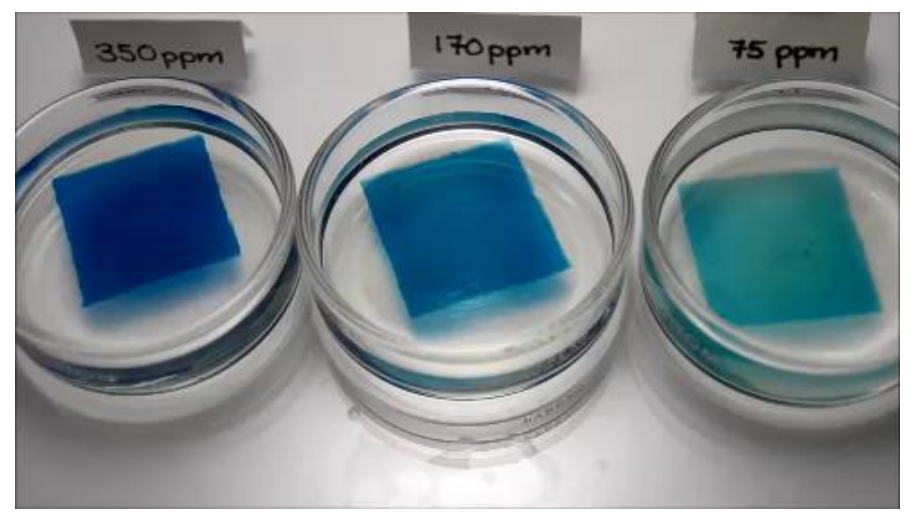

Video 2. Depicts the process of removing the excess ferricyanide from the gels. Note that the 30 min soak is typically repeated with fresh electrolyte, not shown here for brevity. The concentrations shown are the concentration within the hydrogel.

Filesize: $4043 \mathrm{~KB}$

Filetype: Audio Video Interleaved (.avi)

Possible required software: Free VLC media player. 